\title{
Activation of Synaptic Group II Metabotropic Glutamate Receptors Induces Long-Term Depression at GABAergic Synapses in CNS Neurons
}

\author{
Zheng-Quan Tang, ${ }^{1}$ Yu-Wei Liu, ${ }^{1 *}$ Wei Shi, ${ }^{1,2 *}$ Emilie Hoang Dinh, ${ }^{1}$ William R. Hamlet, ${ }^{1,2}$ Rebecca J. Curry, ${ }^{1,2}$ \\ and Yong $\mathrm{Lu}^{1,2}$ \\ ${ }^{1}$ Department of Anatomy and Neurobiology, College of Medicine, Northeast Ohio Medical University, Rootstown, Ohio 44272, and ${ }^{2}$ School of Biomedical \\ Sciences, Kent State University, Kent, Ohio 44240
}

\begin{abstract}
Metabotropic glutamate receptor (mGluR)-dependent homosynaptic long-term depression (LTD) has been studied extensively at glutamatergic synapses in the CNS. However, much less is known about heterosynaptic long-term plasticity induced by mGluRs at inhibitory synapses. Here we report that pharmacological or synaptic activation of group II mGluRs (mGluR II) induces LTD at GABAergic synapses without affecting the excitatory glutamatergic transmission in neurons of the chicken cochlear nucleus. Coefficient of variation and failure rate analysis suggested that the LTD was expressed presynaptically. The LTD requires presynaptic spike activity, but does not require the activation of NMDA receptors. The classic cAMP-dependent protein kinase A signaling is involved in the transduction pathway. Remarkably, blocking mGluR II increased spontaneous GABA release, indicating the presence of tonic activation of mGluR II by ambient glutamate. Furthermore, synaptically released glutamate induced by electrical stimulations that concurrently activated both the glutamatergic and GABAergic pathways resulted in significant and constant suppression of GABA release at various stimulus frequencies $(3.3,100$, and $300 \mathrm{~Hz})$. Strikingly, low-frequency stimulation $(1 \mathrm{~Hz}, 15 \mathrm{~min})$ of the glutamatergic synapses induced heterosynaptic LTD of GABAergic transmission, and the LTD was blocked by mGluR II antagonist, indicating that synaptic activation of mGluR II induced the LTD. This novel form of long-term plasticity in the avian auditory brainstem may play a role in the development as well as in temporal processing in the sound localization circuit.
\end{abstract}

\section{Introduction}

Long-term depression (LTD), a persistent reduction in synaptic efficacy, can be triggered by pharmacological and/or synaptic activation of metabotropic glutamate receptors (mGluRs) in the CNS (Collingridge et al., 2010; Castillo et al., 2011). Among the three groups of mGluRs, mGluR II is widely expressed at both excitatory and inhibitory synapses in the CNS (Ohishi et al., 1993a,b, 1998). A large body of research has shown that activation of mGluR II induces LTD (mGluR II-LTD) at glutamatergic synapses in many brain regions, such as hippocampal CA3 (Kobayashi et al., 1996; Yokoi et al., 1996; Domenici et al., 1998; Tzounopoulos et al., 1998), hippocampal CA1 (ManahanVaughan, 1997; Li et al., 2002), medial perforant path-dentate gyrus (Huang et al., 1997, 1999; Kulla et al., 1999; Pöschel and Manahan-Vaughan, 2005), prefrontal cortex (Otani et al., 1999, 2002; Huang et al., 2007), perirhinal cortex (McCaffery et al.,

\footnotetext{
Received Jan. 15, 2013; revised Aug. 28, 2013; accepted Aug. 31, 2013.

Author contributions: Y.L. designed research; Z.-Q.T., Y.-W.L., W.S., E.H.D., W.R.H., R.J.C., and Y.L. performed research; Z.-Q.T., Y.-W.L., W.S., E.H.D., W.R.H., R.J.C., and Y.L. analyzed data; Z.-Q.T. and Y.L. wrote the paper.

This work was supported by National Institute on Deafness and Other Communication Disorders Grant R01DC008984 (Y.L.). We thank Dr. Joshua Gittelman for helpful discussion and comments.

*Y.-W.L. and W.S. contributed equally to this work.

The authors declare no competing financial interests.

Correspondence should be addressed to Yong Lu at the above address. E-mail: ylu@neomed.edu.

DOI:10.1523/JNEUROSCI.0202-13.2013

Copyright $\odot 2013$ the authors $\quad 0270-6474 / 13 / 3315964-14 \$ 15.00 / 0$
}

1999; Cho et al., 2000), entorhinal cortex (Wang et al., 2012), corticostriatal (Kahn et al., 2001), amygdala (Lin et al., 2000), and nucleus accumbens (Robbe et al., 2002). In striking contrast, to the best of our knowledge, nothing is known as to whether activation of mGluR II can induce heterosynaptic long-term plasticity at inhibitory synapses.

In the avian sound localization circuit, cochlear nucleus magnocellularis (NM) represented a highly likely place for the presence of mGluR II-induced heterosynaptic LTD of inhibitory synapses because of its highly specialized morphological arrangement of excitatory and inhibitory synapses. NM neurons (homolog to mammalian bushy cells) have few or no short dendrites (Jhaveri and Morest, 1982). From the auditory nerve, each NM neuron receives only a few (one to three) large glutamatergic synapses called the end bulbs of Held (Ryugo and Parks, 2003), which cover the majority $(\sim 60 \%)$ of the somatic area (Parks, 1981). GABAergic synaptic terminals, primarily originating from the ipsilateral superior olivary nucleus (SON) (Yang et al., 1999; Burger et al., 2005), form bouton-like puncta that impinge onto NM somata and are presumably located near glutamatergic terminals (Code et al., 1989; Lachica et al., 1994). Heterosynaptic interactions between the glutamatergic and GABAergic pathways to NM bear functional implications. For example, GABA regulates glutamate release via presynaptic $\mathrm{GABA}_{\mathrm{B}}$ receptors ensuring high-frequency firing capability of NM neurons (Otis and Trussell, 1996; Brenowitz et al., 1998). Conversely, synaptically released glu- 
tamate could "spillover" to activate mGluRs on the inhibitory terminals and modulate GABAergic transmission ( $\mathrm{Lu}, 2007)$. Previously, we found that the mGluR II agonist DCG-IV $\left[\left(2 S, 2^{\prime} R, 3^{\prime} R\right)-2-\left(2^{\prime}, 3^{\prime}-\right.\right.$ dicarboxycyclopropyl)glycine] suppressed GABAergic synaptic responses, and the recovery was incomplete after washout of the agonist up to $20 \mathrm{~min}$ (Lu, 2007). Thus, we hypothesized that activation of mGluR II induced LTD at GABAergic synapses in NM neurons. Here, we provide evidence to support this hypothesis. Our finding represents a novel form of heterosynaptic plasticity in the CNS.

\section{Materials and Methods}

Electrophysiology. Brainstem slices (300 $\mu \mathrm{m}$ in thickness) were prepared from white leghorn chick embryos (E17-E20) of both sexes, as described previously (Tang et al., 2011). The ice-cold artificial CSF (ACSF) used for dissecting and slicing the brain tissue contained the following (in $\mathrm{mM}$ ): 250 glycerol, $3 \mathrm{KCl}, 1.2 \mathrm{KH}_{2} \mathrm{PO}_{4}, 20 \mathrm{NaHCO}_{3}, 3 \mathrm{HEPES}, 1.2 \mathrm{CaCl}_{2}, 5$ $\mathrm{MgCl}_{2}$, and 10 glucose, pH 7.4 (when gassed with $95 \% \mathrm{O}_{2}$ and $5 \% \mathrm{CO}_{2}$ ). The procedures have been approved by the Institutional Animal Care and Use Committee at Northeast Ohio Medical University and are in accordance with National Institutes of Health policies on animal use. Slices were incubated at $34-36^{\circ} \mathrm{C}$ for $>1 \mathrm{~h}$ in normal ACSF containing the following (in $\mathrm{mm}$ ): $130 \mathrm{NaCl}, 26 \mathrm{NaHCO}_{3}, 3 \mathrm{KCl}, 3 \mathrm{CaCl}_{2}, 1 \mathrm{MgCl}_{2}$, $1.25 \mathrm{NaH}_{2} \mathrm{PO}_{4}$, and 10 glucose, $\mathrm{pH}$ 7.4. For recording, slices were transferred to a $0.5 \mathrm{ml}$ chamber mounted on a Zeiss Axioskop 2 FS Plus microscope with a $40 \times$ water-immersion objective and infrared differential interference contrast optics. The chamber was continuously superfused with $\operatorname{ACSF}(\sim 2 \mathrm{ml} / \mathrm{min})$ by gravity. Recordings were performed at $34-36^{\circ} \mathrm{C}$.

Patch pipettes were drawn on an Electrode Puller PP-830 (Narishige) to $1-2 \mu \mathrm{m}$ tip diameter using borosilicate glass micropipettes (inner diameter of $0.86 \mathrm{~mm}$, outer diameter of $1.60 \mathrm{~mm}$; VWR Scientific). The electrodes had resistances between 2 and $4 \mathrm{M} \Omega$ when filled with a solution containing the following (in mM): $105 \mathrm{~K}$-gluconate, $35 \mathrm{KCl}, 5 \mathrm{EGTA}$, 10 HEPES, $1 \mathrm{MgCl}_{2}, 4$ ATP-Mg, and 0.3 GTP-Na, pH 7.2 (adjusted with $\mathrm{KOH}$ and osmolarity between 280 and $290 \mathrm{mOsm} / \mathrm{L}$ ). The $\mathrm{Cl}^{-}$concentration $(37 \mathrm{~mm})$ in the internal solution approximated the physiological $\mathrm{Cl}^{-}$concentration (Monsivais and Rubel, 2001) in NM neurons. The liquid junction potential was $10 \mathrm{mV}$, and data were corrected accordingly. Voltage- and current-clamp experiments were performed with an AxoPatch 200B and an AxoClamp 2B amplifier, respectively (Molecular Devices). Voltage-clamp recordings were obtained at a holding potential of $-70 \mathrm{mV}$, and current-clamp recordings were obtained at the resting membrane potential (RMP). Data were low-pass filtered at $3-10 \mathrm{kHz}$ and digitized with a Data Acquisition Interface ITC-18 (Instrutech) at 20 $\mathrm{kHz}$. Recording protocols were written and run using the acquisition and analysis software AxoGraph X (AxoGraph Scientific).

Extracellular stimulation was performed using concentric bipolar electrodes with a tip core diameter of $127 \mu \mathrm{m}$ (World Precision Instruments). The stimulating electrodes were placed using a Micromanipulator NMN-25 (Narishige) and were positioned at an area lateral to the $\mathrm{NM}$, in which the auditory nerve fibers and the GABAergic fibers from the SON mix and travel together into the NM. Such placement of the stimulating electrodes could evoke one of the following responses in a particular recorded NM neuron under normal ACSF perfusion: EPSC only, IPSC only, or EPSC plus IPSC. The observation of the responses in the third category depends on the intensity of the stimulus. In some neurons, low-intensity stimuli evoked EPSC only, and higher-intensity stimuli evoked both EPSC and IPSC. In other neurons, low-intensity stimuli evoked IPSC only, and higher intensity stimuli evoked both IPSC and EPSC. The selection of cells depends on the experimental design. For the experiments in which the modulatory effects of mGluRs were studied by application of exogenous agonists or antagonists, results were collected from neurons in which the responses under investigation (IPSCs or EPSCs) were evoked. For the experiments in which the effects of synaptically released glutamate on the IPSCs were studied, only neurons from which both EPSC and IPSC could be evoked were used. Square electric pulses (duration of $200 \mu$ s) were delivered through a Stimulator
A320RC (World Precision Instruments). Optimal stimulation parameters were selected for each cell to give reliable postsynaptic responses. IPSCs were recorded (once every $30 \mathrm{~s}$, for $>1 \mathrm{~h}$ ) in the presence of DNQX $(50 \mu \mathrm{M})$, an antagonist for AMPA receptors. EPSCs and EPSPs were recorded in the presence of $\mathrm{GABA}_{\mathrm{A}}$ receptor $\left(\mathrm{GABA}_{\mathrm{A}} \mathrm{R}\right)$ antagonist SR95531 [2-(3carboxypropyl)-3-amino-6-(4-methoxyphenyl)pyridazinium bromide] (10 $\mu \mathrm{M})$ and glycinergic receptor antagonist strychnine $(1 \mu \mathrm{M})$. Because of the fluctuation in amplitude of individual IPSCs, the first 20 IPSCs before drug application were averaged, the averaged value was treated as the control, and each IPSC was normalized to this averaged value and plotted against time. Graphs were made in Igor (Wavemetrics). Means and SEM are reported. Statistical differences were determined by $t$ test or ANOVA post hoc Fisher's test.

All chemicals and drugs were obtained from Sigma, except for DCG-IV, LY341495 [(2S)-2-amino-2-[(1S,2S)-2-carboxycycloprop-1-yl]-3-(xanth9-yl) propanoic acid], LY354740 [(+)-2-aminobicyclo[3.1.0]-hexane-2, 6-dicarboxylate monohydrate],3,5-DHPG [(RS)-3,5-dihydroxyphenylglycine], L-AP-4, SQ22536 [9-(tetrahydro-2' -furyl)adenine], KT5720 [(9S,10 R,12R) -2,3,9,10,11,12-hexahydro-10-hydroxy-9-methyl-1-oxo-9,12-epoxy-1 $H$-diindolo[1,2,3-fg: $3^{\prime}, 2^{\prime}, 1^{\prime}$-kl]pyrrolo[3,4-i] [1,6] benzodiazocine-10carboxylicacid hexyl ester], and CPPG $[(R S)$ - $\alpha$-cyclopropyl-4-phosphonophenylyglycine], which were obtained from Tocris Bioscience. Drugs were bath applied using a gravity-driven perfusion system.

Group II mGluR immunostaining and Western blot. All reagents for immunostaining were purchased from Sigma unless otherwise indicated. Chick embryos (E13-E18), 1- or 2-d-old post-hatch chicks (P1-P2), and 1-week-old hatchlings (P7-P9) were used to study the expression of mGluR II using a specific polyclonal antibody against both mGluR2 and mGluR3 (Abcam). Embryos were decapitated, and the brains were immediately immersed in a fixative solution of $4 \%$ paraformaldehyde (PFA), pH 7.4, whereas hatched animals were deeply anesthetized with Fatal-Plus (Vortech Pharmaceuticals) and transcardially perfused with PFA. The brains were dissected out, postfixed in PFA for $2 \mathrm{~h}$ at room temperature $(\mathrm{RT})$ and then overnight $(\mathrm{O} / \mathrm{N})$ at $4^{\circ} \mathrm{C}$, rinsed thoroughly in PBS ( $\mathrm{pH} 7.4$ ), and vibratome sliced (50 $\mu \mathrm{m}$ in thickness).

The free-floating sections were rinsed in PBS. Endogenous peroxidase activity was quenched for $30 \mathrm{~min}$ in $3 \% \mathrm{H}_{2} \mathrm{O}_{2}$ (in $80 \%$ methanol-PBS), and nonspecific binding sites were blocked for $2 \mathrm{~h}$ in $5 \%$ normal goat serum (in $0.5 \%$ Triton X-100-PBS). For antigen retrieval, sections were heated $\left(70-90^{\circ} \mathrm{C}\right)$ in sodium citrate buffer $(0.05 \mathrm{M})$ and $0.9 \% \mathrm{NaCl}$ solution for $60 \mathrm{~min}$. Sections were incubated with the primary antibody (1:500 in $2 \%$ bovine serum albumin, $0.5 \%$ Triton X-100-PBS, O/N at $\mathrm{RT}$ ), followed by incubation with the biotinylated anti-rabbit secondary antibody (1:400; Abcam) for $2 \mathrm{~h}$ at RT. The signal was amplified using an avidin-biotin-horseradish peroxidase-based system (Vector Laboratories). Sections were rinsed in Tris-buffered saline (TBS), $\mathrm{pH}$ 7.4, before nickel-diaminobenzidine reaction, mounted on slides, and allowed to air dry $(\mathrm{O} / \mathrm{N}$ at RT). Finally, slices were dehydrated by an ascending ethanol series, cleared in xylene, and coverslipped using Permount mounting media (Thermo Fisher Scientific). Negative control experiments were performed with omission of the primary antibody. Images were taken with a high-resolution CCD camera system (Spot camera; Diagnostic Instruments) mounted on an Olympus Provis AX70 microscope.

All reagents for Western blot analysis were purchased from Thermo Fisher Scientific unless otherwise stated. Eight chicks (P1-P3) were deeply anesthetized by isoflurane inhalation (Aerrane; Baxter International) and rapidly decapitated. The brains were immediately dissected out in ice-cold ACSF. Tissues of interest were collected into vials filled with lysis buffer: $10 \mathrm{~mm}$ Tris $\mathrm{HCl}, 100 \mathrm{~mm} \mathrm{NaCl}, 1 \mathrm{~mm}$ EDTA, $1 \mathrm{~mm}$ EGTA, and 1\% SDS, pH 6.8. After homogenizing the tissues, total proteins were extracted by centrifugation, and their concentration was determined by BCA assay (Thermo Fisher Scientific). Proteins were loaded (50 $\mu \mathrm{g} /$ lane) and separated by $10 \%$ SDS-PAGE and then wet transferred onto PVDF membranes $(100 \mathrm{~V}, 1 \mathrm{~h})$, which were blocked in $5 \%$ skim milk and TBS-Tween 20 (TBS-T), pH 7.5 (for $1 \mathrm{~h}$ at RT), before incubation with anti-mGluR2/3 antibody ( $1: 1000$ in blocking buffer, $\mathrm{O} / \mathrm{N}$ at $\left.4^{\circ} \mathrm{C}\right)$. Membranes were then rinsed three times ( $10 \mathrm{~min}$ each) in TBS-T (and before all subsequent steps), incubated $1 \mathrm{~h}$ with horseradish peroxidase-conjugated goat anti-rabbit-IgG (1:3000; Bio-Rad), pro- 


\begin{tabular}{|c|c|c|c|c|c|}
\hline \multirow[b]{2}{*}{ Figure } & \multicolumn{5}{|c|}{ Number of cells } \\
\hline & Total & IPSC only & IPSC + EPSC & IPSC (EPSC unknown) & EPSC only \\
\hline 1 & 72 & 39 & 18 & 15 & NA \\
\hline 3 & 19 & 10 & 9 & 0 & NA \\
\hline 5 & 35 & 16 & 5 & 14 & NA \\
\hline 7 & 56 & 7 & 43 & 0 & 6 \\
\hline 8 & 19 & 0 & 19 & 0 & NA \\
\hline 9 & 18 & 7 & 3 & 0 & 8 \\
\hline Total & 219 & 79 & 97 & 29 & 14 \\
\hline
\end{tabular}

NA (not applicable) indicates that cells with EPSC only were discarded for these experiments.

cessed for chemiluminescent reaction ( 5 min; ECL kit; Thermo Fisher Scientific), and developed on film.

\section{Results}

Using whole-cell recordings, we collected electrophysiological data from a total of $240 \mathrm{NM}$ neurons. We studied the evoked synaptic responses (IPSCs or EPSCs) in 219 cells. Under normal ACSF perfusion, three synaptic response types were observed in a particular recorded cell: IPSC only, EPSC only, or IPSC plus EPSC. The quantitative categorization of these response types is presented in Table 1.

\section{Activation of mGluR II induces LTD at GABAergic synapses}

We performed long-lasting $(>1 \mathrm{~h}$ ) whole-cell recordings from NM neurons in brain slices and determined the effects of mGluR II agonists on IPSCs elicited by electrical stimulation (single pulse, once every $30 \mathrm{~s}$ ) of the GABAergic pathway. Individual IPSCs fluctuated widely in amplitude (Fig. 1A), consistent with previous studies (Lu and Trussell, 2000; Lu, 2007). When recorded without any pharmacological manipulations, IPSCs remained stable for $>1 \mathrm{~h}(n=8$; Fig. $1 B)$. In the experimental group, after $>10$ min baseline recording of IPSCs, we bath applied DCG-IV $(4 \mu \mathrm{M})$, a specific agonist for mGluR II for $10 \mathrm{~min}$. Within 2 min of application, DCG-IV induced an initial strong depression of IPSCs, which persisted for $\sim 15$ min after the washout of DCG-IV. After continuous washout, a persistent reduction in the amplitude of IPSCs $(n=14$; Fig. $1 C, D)$ was observed. This DCG-IV-induced persistent reduction of IPSCs, defined as mGluR II-LTD, maintained for as long as the recording was continued. To ensure that the LTD is induced by activation of mGluR II, we tested whether the LTD could be abolished by a highly specific mGluR II antagonist LY341495 (Schoepp et al., 1999). In the presence of LY341495 (3 $\mu \mathrm{M})$, DCG-IV failed to induce LTD $(n=7$; Fig. $1 E)$, consistent with an mGluR II-specific effect (Lu, 2007; Tang and Lu, 2012; Wang et al., 2012). To further confirm that mGluR II induced the LTD, we examined the effect of LY354740, another highly specific mGluR II agonist (Schoepp et al., 1997). LY354740 (1 $\mu \mathrm{M})$ induced an initial transient suppression, followed by a substantial LTD $(n=7$; Fig. $1 F)$. In contrast, 3,5-DHPG (200 $\mu \mathrm{M}, n=5)$ and L-AP-4 $(10 \mu \mathrm{M}, n=7)$, selective agonists for mGluR I and mGluR III, respectively, strongly suppressed IPSCs but did not induce LTD (Fig. 1G,H). Together, these results indicate that activation of mGluR II produces a chemical LTD at GABAergic synapses in NM neurons.

To further confirm the existence of the LTD, we studied the effect of LY341495 alone on the baseline GABA transmission, and, more importantly, the effect of LY341495 during the longlasting suppression of IPSCs. We showed previously that blocking all mGluRs using a mixture of antagonists LY341495 (20 $\mu \mathrm{M})$ and CPPG $(10 \mu \mathrm{M})$ increased significantly the amplitude of IPSCs evoked by train stimulation $(10 \mathrm{~Hz})$ in NM neurons (Lu, 2007). We predicted that LY341495 (3 $\mu \mathrm{M})$ would increase the amplitude of IPSCs evoked by the electrical stimulation protocol for LTD recording (at $0.03 \mathrm{~Hz}$ ), and the results confirmed this prediction $(n=8,140.1 \pm 16.8 \%$ of control, paired $t$ test, $p<0.05$; Fig. $1 I, K)$. Therefore, we expected that LY341495 applied during the induction of the LTD would slightly but not completely reverse the LTD. To address this, during DCG-IV-induced longlasting suppression (20 min after washout of DCG-IV), we applied LY341495 and compared the average amplitude of 20 IPSCs (50-60 min) during LY341495 application ( $n=16$; Fig. $1 J)$ with those recorded during the same time period in the absence of LY341495 (data in Fig. 1D). The suppression of IPSCs in the absence of LY341495 (57.2 $\pm 8.0 \%$ of control, $n=14)$ is stronger than that in the presence of LY341495 (69.1 $\pm 13.1 \%$ of control, $n=16$ ) (Fig. $1 K$, unpaired $t$ test, $p<0.05$ ), suggesting that there may be two components of the suppression during the long-lasting inhibition of IPSCs. One component is likely attributable to tonic mGluR II activity induced by ambient glutamate, and the second component of the inhibition is indeed an LTD, which was partially blocked by LY341495 after the LTD was induced. It is important to note that it is very difficult to disentangle precisely the inhibition caused by tonic mGluR II activity and the mGluR II-LTD because both are long lasting and the tonic mGluR II activity could in theory induce additional LTD. Therefore, the quantitative separation of these two components (Fig. $1 K$ ) is considered approximate.

To support these physiological observations, we examined the expression of mGluR II with immunostaining and Western blot analysis techniques (Fig. 2). Intense immunoreactivity for mGluR II was observed in the auditory brainstem nuclei, including the NM (Fig. 2A,B). To confirm the specificity of immunoreactivity, the cerebellum was used as a positive control. The neuropils in the granular and Purkinje cell layers were intensely labeled, and the molecular layer was moderately labeled as a result of the extension of the dendrites of immunoreactive cells in the granular layer (Fig. 2C,D). The labeling is likely attributable to the immunoreactivity of primarily Golgi cells, similar to the staining in mammalian cerebellum (Neki et al., 1996; Ohishi et al., 1998). However, it is difficult to discern neuronal cell bodies because they were obscured by many varicose structures. We also examined the specificity of the antibody against mGluR II in the chicken by Western blot. We collected tissues from the dorsal brainstem containing NM, the ventral brainstem, cerebrum, and cerebellum. We observed two immunoreactive products of 100 and $200 \mathrm{kDa}$, which corresponded to monomeric and dimeric forms of the two members of mGluR II (mGluR2 and mGluR3), respectively (Fig. 2E). Formation of dimers for mGluRs in Western blot analysis is a common observation across animal species (Shigemoto et al., 1997). In addition, we detected strong expression of mGluR II across the entire coding-frequency axis throughout different developmental stages (Fig. $2 F-N$ ).

\section{mGluR II-LTD at GABAergic synapses requires presynaptic spike activity and is expressed presynaptically}

Previous studies indicate that presynaptic activation is required for the induction of mGluR II-LTD at glutamatergic synapses in some regions of the brain (Huang et al., 1997, 1999; Tzounopoulos et al., 1998; Lin et al., 2000; Jiang et al., 2010). We thus examined whether the induction of LTD at GABAergic synapse depended on synaptic activation of presynaptic GABAergic fibers. The experiments were performed in which synaptic stimulation was stopped during both perfusion and $10 \mathrm{~min}$ washout of 
A

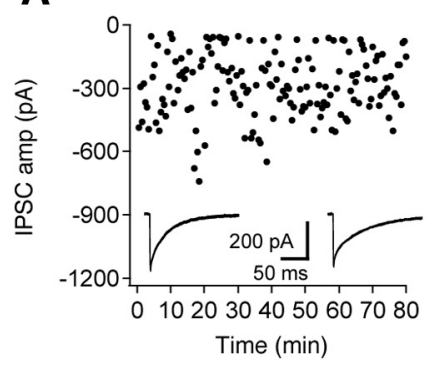

B

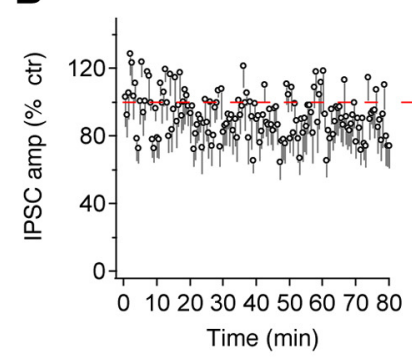

I

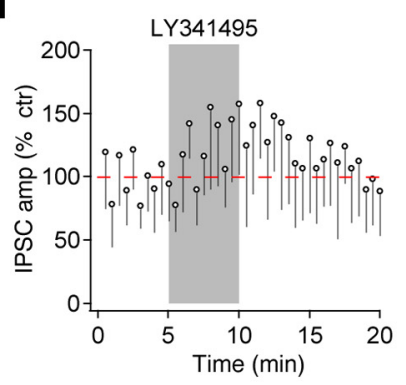

C

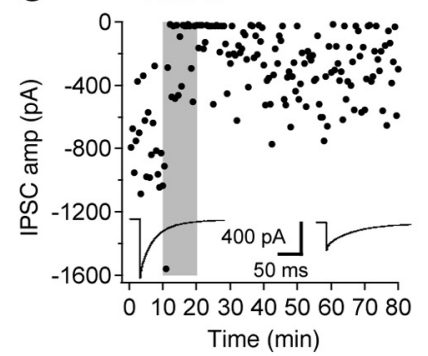

D DCG-IV

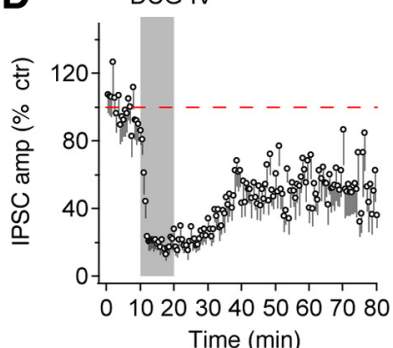

J

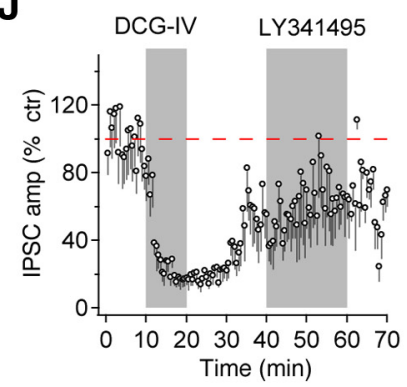

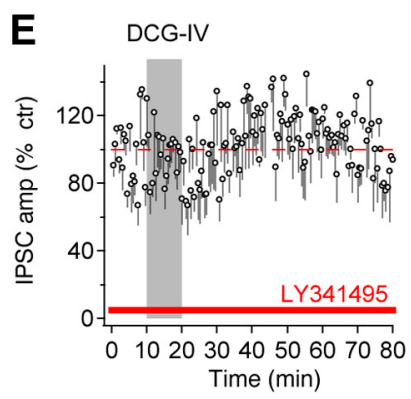
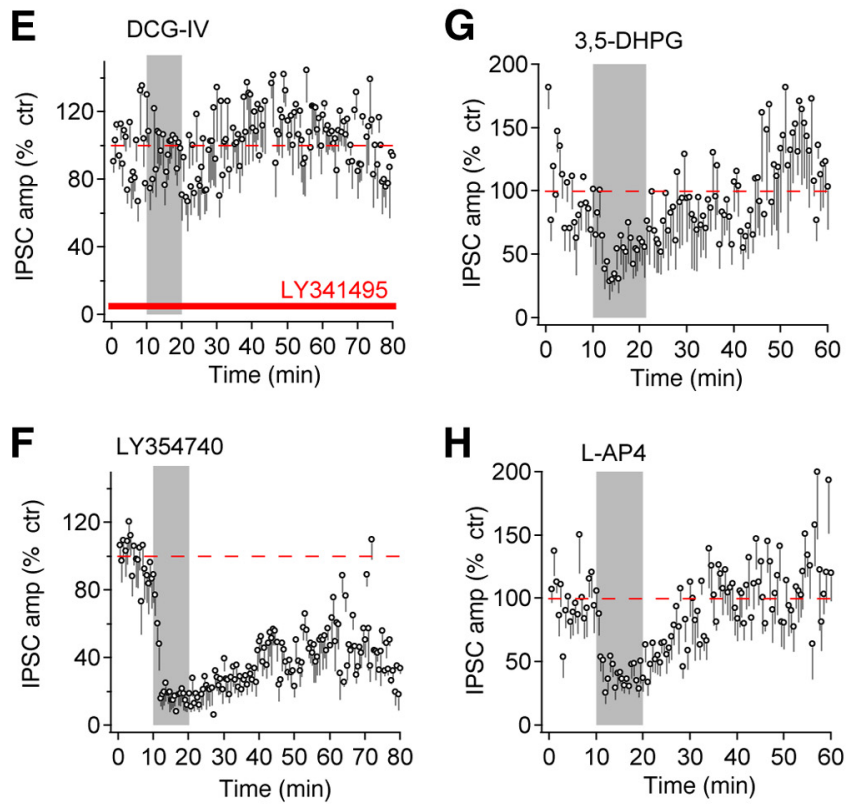

K

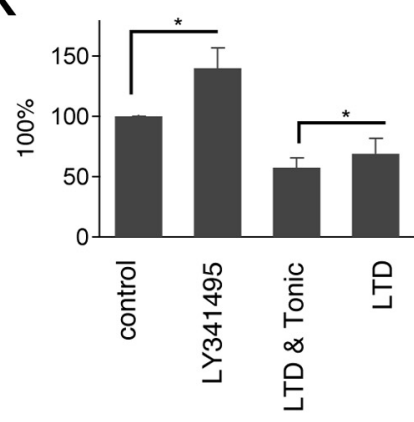

Figure 1. mGluR II agonists induce LTD at GABAergic synapses. $A, B$, Individual IPSCs recorded once every 30 s varied widely in amplitude, but the averaged amplitude remained relatively constant in 80-min recordings $(n=8)$. C, D, Bath-application of an mGluR II agonist DCG-IV $(4 \mu \mathrm{m})$ induced an initial transient suppression, followed by LTD of IPSCS $(n=14)$. $\boldsymbol{E}$, LY341495 (3 $\mu \mathrm{M})$, an antagonist for mGluR II, eliminated the effects of DCG-IV $(n=7) . \boldsymbol{F}$, Another mGluR II agonist, LY354740 $(1 \mu \mathrm{M})$, also induced an initial transient suppression and LTD of IPSCs $(n=7)$. $\boldsymbol{G}, \boldsymbol{H}$, $\mathrm{mGluR}$ I agonist (3,5-DHPG, $200 \mu \mathrm{m} ; n=5)$ or mGluR III agonist (L-AP-4, $10 \mu \mathrm{M} ; n=7)$ produced an initial suppression but not LTD of IPSCs in NM neurons. I, LY341495 (3 $\mu \mathrm{M})$ slightly increased the amplitude of IPSCs evoked at $0.03 \mathrm{~Hz}(n=8) . J$, Application of LY341495 $(3 \mu \mathrm{M})$ during the induction of LTD partially reversed the plasticity $(n=16)$, suggesting the presence of a low level of tonic inhibition mediated by ambient glutamate-activated mGluRII. $\boldsymbol{K}$, Averaged amplitude of IPSCs under the conditions of LY341495 (I), DCG-IV (D), and LY341495 during LTD induction (J), normalized to their respective controls. The red dashed lines indicate the baseline ( $100 \%$ of control). Cells were voltage clamped at $-70 \mathrm{mV}$. Means \pm SEM are shown in this and subsequent figures. ${ }^{*} p<0.05$ ( $t$ test).

DCG-IV. As shown in Figure 3A, DCG-IV application without presynaptic stimulation of the GABAergic afferents failed to induce LTD $(n=7)$. This observation further supports the idea that DCG-IV can be washed out rapidly (Breakwell et al., 1997; Lu and Rubel, 2005). Therefore, the results argue against the possibility that the mGluR II-LTD may be caused by incomplete washout of DCG-IV and thus residual occupancy of mGluR II during washout.

Given the mixed synaptic responses in the cells collected under normal ACSF perfusion for this experiment (four cells with IPSC plus EPSC and three cells with IPSC only; Fig. $3 A$ ), it is difficult to draw a firm conclusion on whether the GABAergic or glutamatergic presynaptic spike activity is important for the induction of the LTD. However, in the cells from which only IPSCs were evoked in ACSF, DCG-IV application without afferent stimulation did not induce LTD of IPSCs. This observation suggests that presynaptic spike activity of the GABAergic terminals is required for the induction of the LTD. To further test this, we asked whether a presynaptic $\mathrm{Ca}^{2+}$ increase in the GABAergic terminals or a postsynaptic $\mathrm{Ca}^{2+}$ increase in NM neurons is required for the LTD. The rationale to investigate $\mathrm{Ca}^{2+}$ signaling is that the requirement of spike activity in long-term plasticity is generally associated with action potential-induced $\mathrm{Ca}^{2+}$ increase at the loci in which the plasticity is induced. We increased the concentration of $\mathrm{Ca}^{2+}$ chelator EGTA inside the recording electrodes from 5 to $15 \mathrm{~mm}$. If a postsynaptic $\mathrm{Ca}^{2+}$ increase were required for the LTD induction, then LTD would not be formed in the presence of high EGTA. We found that DCG-IV induced LTD of IPSCs as it did in the presence of a lower concentration of EGTA ( $n=7$ cells; Fig. $3 D$ ), indicating that postsynaptic $\mathrm{Ca}^{2+}$ signaling is not required for the LTD induction. To test whether the LTD requires presynaptic $\mathrm{Ca}^{2+}$ signaling in the GABAergic terminals, we incubated brain slices in the membrane-permeable $\mathrm{Ca}^{2+}$ chelator BAPTA-AM at a moderate concentration $(10 \mu \mathrm{M})$ for 30-60 min for BAPTA to be accumulated inside the cells and to eliminate $\mathrm{Ca}^{2+}$ increase in the presynaptic terminals (Lin et al., 2000). During the IPSC recordings, a lower concentration of BAPTA-AM $(5 \mu \mathrm{M})$ was continuously applied in the bath. We chose not to use too high concentrations of BAPTA-AM nor too long incubation time, which could diminish synaptic responses, dramatically leading to difficulty of studying very small IPSCs. Because BAPTA-AM treatment does not selectively target 

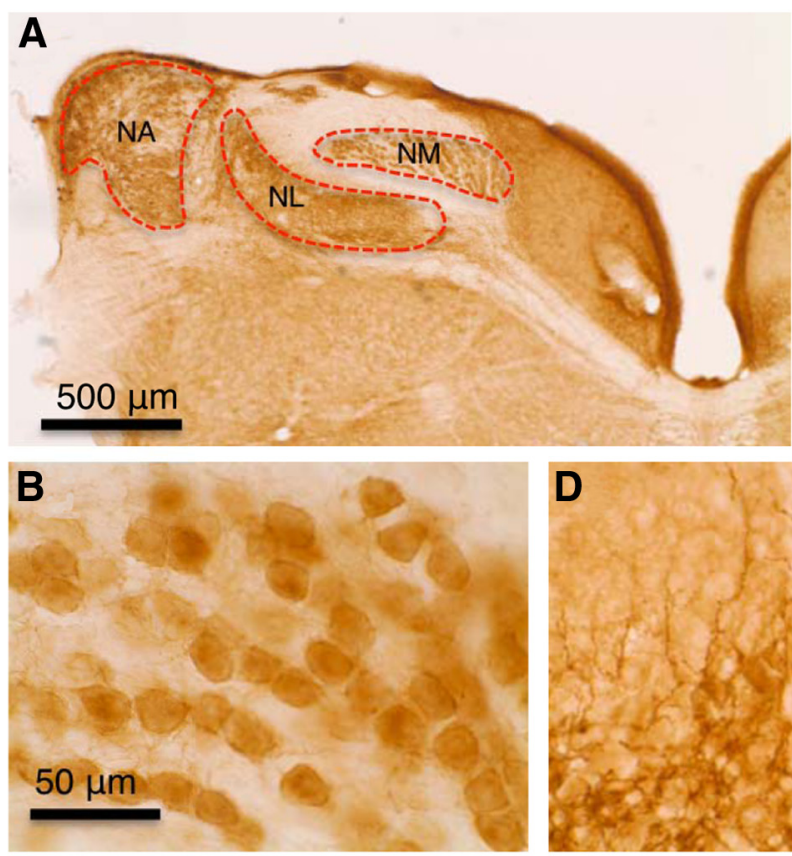

embryo (E18)
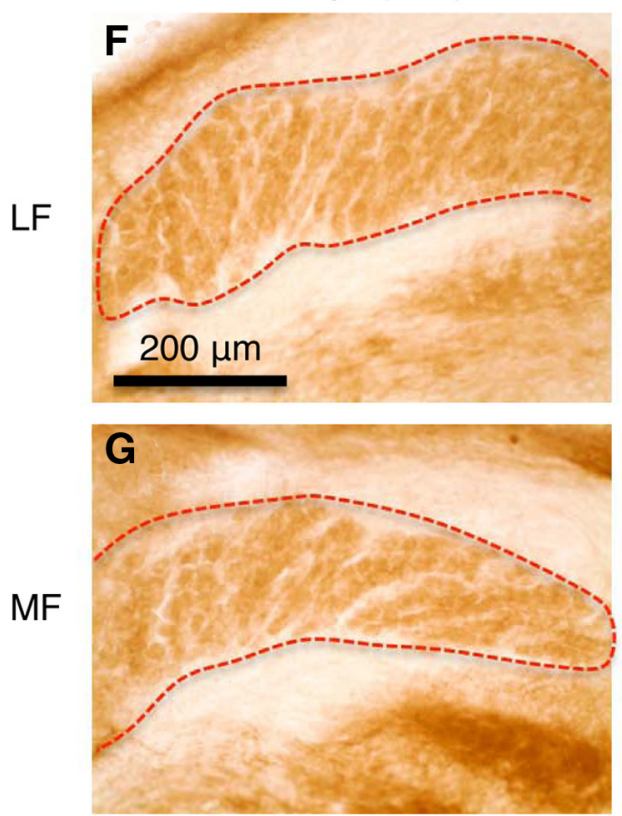

H

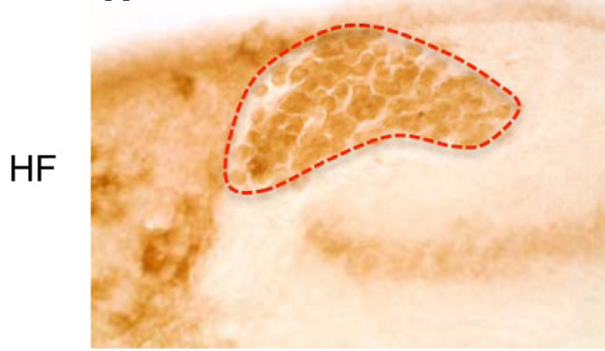

C

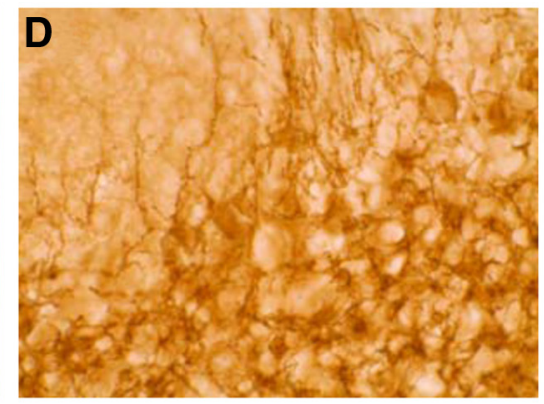

$\mathbf{E}$

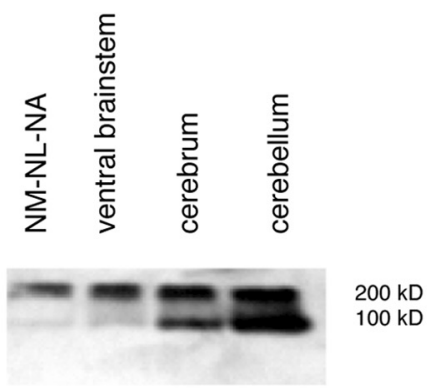

hatchling (P9)
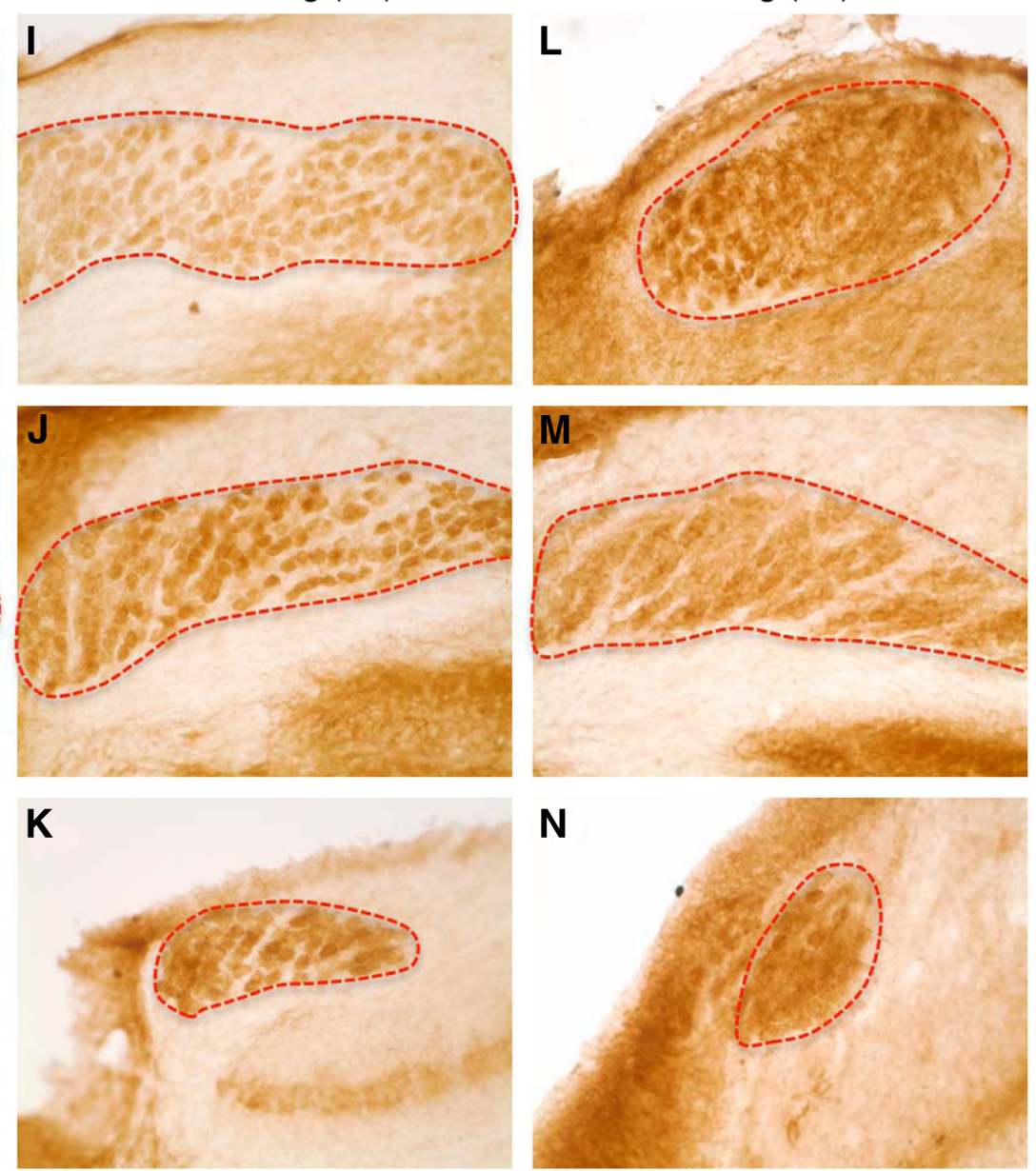

Figure 2. mGluR II is expressed in NM neurons throughout the entire tonotopic axis across different ages. $A$, Immunohistochemistry revealed expression of mGluR II in auditory brainstem nuclei. NA, Nucleus angularis; NL, nucleus laminaris. $\boldsymbol{B}$, Part of the NM shown at a higher amplification. $\boldsymbol{C}, \boldsymbol{D}$, Expression of $\mathrm{mGluR} I I$ in the cerebellar cortex used as a positive control. The neuropils in the granular and Purkinje cell layers were intensely labeled, and the molecular layer was moderately labeled as a result of the extension of the dendrites of immunoreactive cells (primarily Golgi cells) in the granular layer. $\boldsymbol{E}$, Western blot confirmed the specificity of the antibody against mGluR II in chicken brain tissues. The two immunoreactive products of 100 and $200 \mathrm{kDa}$ correspond to monomeric and dimeric forms of mGluR2/3, respectively. $\boldsymbol{F}-\boldsymbol{N}$, Expression of $\mathrm{mGluR} I I$ in different characteristic frequency regions (LF, MF, and $H F$ indicate low, middle, and high frequency, respectively) in $\mathrm{E} 18$ ( $n=2$ animals; $\boldsymbol{F}-\boldsymbol{H}), 1$ - or 2-d-old post-hatch chicks (P1-P2, $n=5$ animals; $\boldsymbol{I}-\boldsymbol{K})$, and 1-week-old chicks (P7-P9, $n=2$ animals; $\boldsymbol{L}-\boldsymbol{N}$ ). 

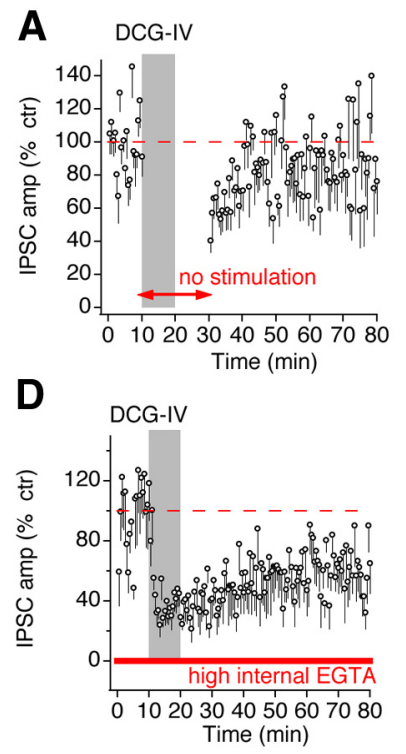
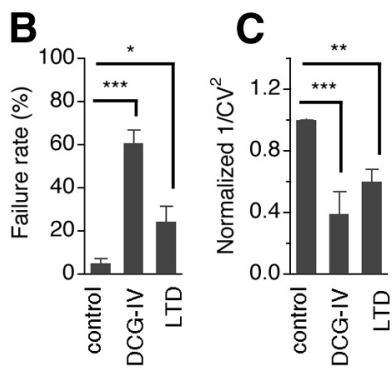

E

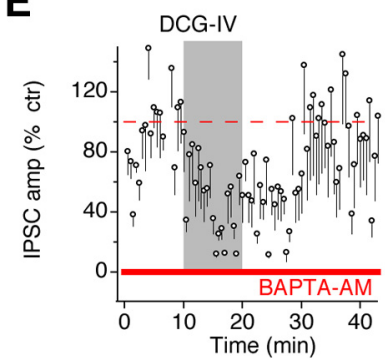

A

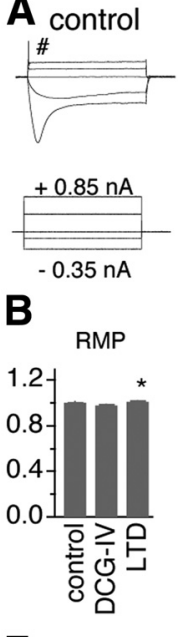

F

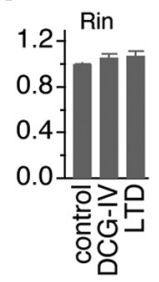

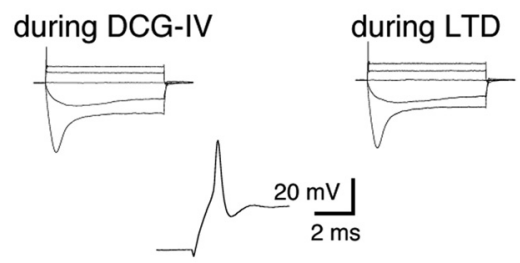

C current D
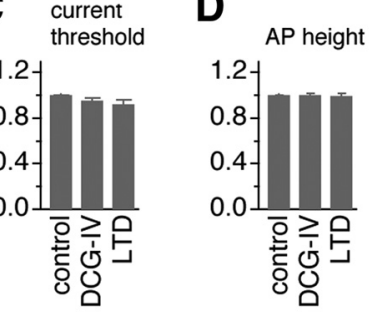

E
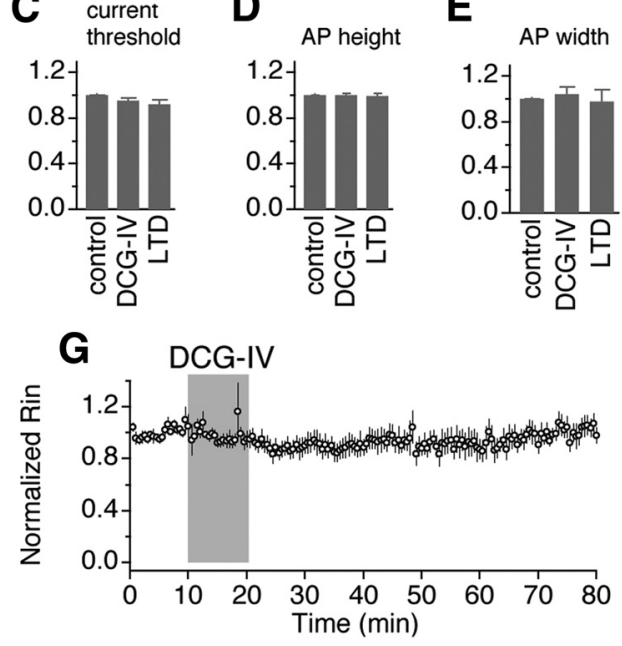

Figure 3. The mGluR I-LTD requires presynaptic spike activity and is expressed presynaptically. $\boldsymbol{A}, \mathrm{DCG}-\mathrm{IV}(4 \mu \mathrm{m})$ application without electrical stimulation of the GABAergic afferents failed to induce LTD $(n=7) . \boldsymbol{B}, \boldsymbol{C}$, mGluRII-LTD was accompanied by changes in failure rate and the CV of IPSCs. DCG-IV increased the failure rate $(p=0.0169, n=14)$ and decreased $1 / \mathrm{CV}^{2}$ ( $p=0.0063, n=14$ ) of IPSC s during LTD, indicating presynaptic actions of mGluR II. D, DCG-IV $(4 \mu \mathrm{m})$ induced approximately the same level of LTD with high EGTA in recording electrodes $(n=7)$. $E$, BAPTA-AM treatment ( $10 \mu \mathrm{M}, 30-60$ min incubation followed by perfusion at a lower concentration, $5 \mu \mathrm{m}$, throughout the recording) of the brain slices essentially eliminated DCG-IV-induced LTD of IPSCs $(n=5)$. ${ }^{*} p<0.05,{ }^{* *} p<0.01,{ }^{* * *} p<0.001$ (ANOVA post hoc Fisher's test).

GABAergic terminals, we applied the LTD recording protocol to cells that showed IPSCs only in ACSF. DCG-IV induced much smaller LTD of IPSCs after BAPTA incubation (Fig. 3E), suggesting that an action potential-induced presynaptic $\mathrm{Ca}^{2+}$ increase in the GABAergic terminals is possibly required for the LTD.

In different areas of the brain, mGluR II can be located presynaptically or postsynaptically (Nicoletti et al., 2011). To identify the locus of the expression of mGluR II-LTD at GABAergic synapses in NM neurons, we performed analyses on failure rate and coefficient of variation (CV) of IPSCs, under the conditions of control, during DCG-IV (initial suppression), and after washout of DCG-IV (LTD induction). Changes in failure rate and CV indicate alterations in presynaptic release probability (Faber and Korn, 1991). We observed a significant increase in failure rate (Fig. 3B; control, $5.0 \pm 2.1 \%$; DCG-IV, $60.7 \pm 6.0 \%, p<0.0001$; LTD, $24.2 \pm 7.0 \%, p<0.05 ; n=14)$ both during the initial suppression and the LTD of IPSCs, suggesting a presynaptic mechanism of mGluR II action. There was also a significant decrease in normalized $1 / \mathrm{CV}^{2}$ during DCG-IV and LTD (Fig. $3 C$; DCG-IV, $38.8 \pm 14.5 \%$ of the control, $p<0.0001$; LTD, $60.2 \pm$ $7.8 \%$ of the control, $p<0.01 ; n=14$ ). These data indicate that the LTD results from a persistent reduction in the release probability at the GABAergic synapses. To further confirm the presynaptic expression of mGluR II-LTD at GABAergic synapses, we examined the effects of DCG-IV on the intrinsic excitability of NM neurons. We observed little effect of DCG-IV on normalized RMP, current threshold, action potential height and width, and input resistance $\left(R_{\text {in }}\right)$ under either current-clamp $(n=7$; Fig. $4 A-F)$ or voltage-clamp $(n=14$; Fig. $4 G)$ recordings, presumably excluding postsynaptic mechanisms. Therefore, the induction of LTD at GABAergic synapses in NM neurons is primarily presynaptic, consistent with the presynaptic expression of

Figure 4. mGluR Il agonists do not change the excitability of NM neurons. $\boldsymbol{A}$, Representative membrane potential recordings in response to prolonged $(200 \mathrm{~ms})$ somatic current injections under the conditions of control, DCG-IV $(4 \mu \mathrm{M}$ ), and LTD (45 min after termination of DCG-IV application). The action potential (labeled with the symbol \#) waveform under the control condition is shown at larger scales. $\boldsymbol{B}-\boldsymbol{F}$, Normalized RMPs, current thresholds, action potential (AP) height and width, and $R_{\text {in }}$ remained essentially unchanged between control and during/ after DCG-IV application ( $n=7)$, presumably excluding postsynaptic mechanisms of the LTD induction by mGluR II. $G, R_{\text {in }}$ of NM neurons obtained under voltage-clamp recordings remained unchanged ( $n=14$ ) during LTD induction. ${ }^{*} p<0.05$ (ANOVA post hoc Fisher's test).

mGluR II-LTD at glutamatergic synapses in some regions of the brain (Lin et al., 2000; Pöschel and Manahan-Vaughan, 2005; Wang et al., 2012).

Although these physiological results and our previous data (Lu, 2007) demonstrate presynaptic actions of mGluR II, the anatomy data (Fig. 2) showed primarily somatic rather than punctate labeling of mGluR II. It is well known that $\mathrm{Ca}^{2+}$ signaling of NM neurons is regulated by multiple postsynaptic mGluRs (Rubel and Fritzsch, 2002), including mGluR II (Lu and Rubel, 2005). Therefore, the explanation for this discrepancy may be that the expression of mGluR II on GABAergic terminals is masked by robust postsynaptic immunoreactivity.

\section{mGluR II-LTD at GABAergic synapses is independent of NMDA receptors and involves CAMP/PKA signaling}

Because DCG-IV at a high concentration $(10-15 \mu \mathrm{M})$ activates NMDA receptors (NMDARs; Wilsch et al., 1994; Breakwell et al., 1997) and activation of NMDARs is required for some forms of long-term plasticity at GABAergic synapses in the brain (Lien et al., 2006; Castillo et al., 2011), we determined whether pharmacological blockade of NMDARs affected the mGluR II-LTD of GABAergic synapses in NM. As shown in Figure 5A, bath application of the NMDAR antagonist APV $(50 \mu \mathrm{M})$ did not affect the LTD $(n=6)$, indicating that the expression of the LTD does not require activation of NMDARs.

We next investigated the signaling mechanisms underlying mGluR II-LTD at GABAergic synapses. mGluR II are known to 

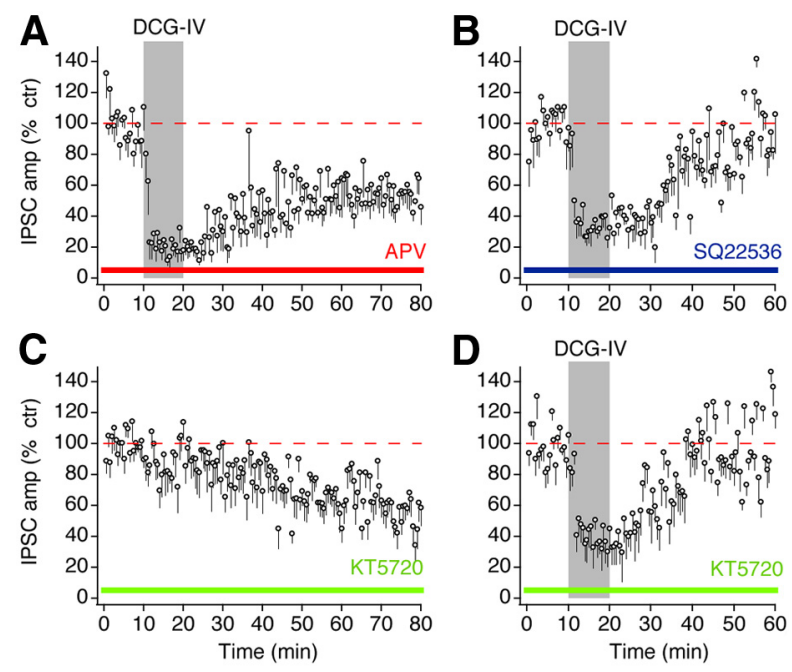

Figure 5. The LTD is NMDAR independent and mediated by the classic cAMP/PKA signaling pathway. $\boldsymbol{A}$, The LTD persisted in the presence of the NMDAR antagonist APV $(50 \mu \mathrm{M}, n=6) \cdot \boldsymbol{B}$, Blocking AC by SQ22536 (50 $\mu \mathrm{M}, n=8)$ eliminated the LTD without affecting the initial inhibition. C, KT5720 (1 $\mu \mathrm{M}, n=9)$, an antagonist for PKA, gradually reduced IPSCs, and the effects stabilized in $\sim 1 \mathrm{~h}$. $\boldsymbol{D}$, Incubation of brain slices for $1 \mathrm{~h}$ in ACSF containing KT5720 (1 $\mu \mathrm{M}, n=$ 12) occluded the induction of LTD.

couple to $\mathrm{G}_{\mathrm{i}}$-proteins, and activation of $\mathrm{G}_{\mathrm{i}}$-proteins results in decreased activity of adenylyl cyclase (AC) and subsequent reduction in cAMP and suppression of PKA (Pin and Acher, 2002). To determine whether AC activity is required for mGluR II-LTD, we incubated brain slices in ACSF containing the AC inhibitor SQ22536 $(50 \mu \mathrm{M})$ for $1 \mathrm{~h}$ and then repeated the LTD protocol during which SQ22536 was present. Under these conditions, DCG-IV $(4 \mu \mathrm{M})$ failed to induce LTD $(n=8$; Fig. $5 B)$. The initial suppression of IPSCs was not affected, possibly because it was mediated by a membrane-delimited pathway whereby the G-protein $\beta \gamma$ complex inhibits voltage-gated $\mathrm{Ca}^{2+}$ channels (Herlitze et al., 1996). We then determined whether PKA is involved in mGluR II-LTD. Application of KT5720 (1 $\mu \mathrm{M})$, a selective PKA inhibitor, led to a progressive reduction in IPSCs, and the effects stabilized within $1 \mathrm{~h}(n=9$; Fig. $5 C)$. Therefore, we incubated slices in ACSF containing KT5720 $(1 \mu \mathrm{M})$ for $1 \mathrm{~h}$ and then repeated the LTD protocol in the presence of KT5720. KT5720 completely abolished the LTD without blocking the initial depression $(n=12$; Fig. $5 D)$. Together, our findings demonstrate that mGluR II-LTD at GABAergic synapses is associated with inhibition of AC and CAMP-dependent PKA, consistent with the mechanisms underlying mGluR II-induced LTD at some glutamatergic synapses (Tzounopoulos et al., 1998; Huang et al., 1999, 2007; Lin et al., 2000; Robbe et al., 2002; Bellone et al., 2008).

\section{Activation of mGluR II by endogenous glutamate and synaptically induced heterosynaptic LTD at GABAergic synapses}

Although the above results demonstrate that activation of mGluR II by exogenous agonists induced an initial suppression followed by LTD at GABAergic synapses, a more physiologically relevant question is whether mGluR II can be activated by endogenous glutamate. Presynaptic mGluR II can be activated by ambient glutamate (Chu and Moenter, 2005), synaptically released glutamate, or glutamate spillover from neighboring synapses (Mitchell and Silver, 2000; Tang et al., 2009). To find out whether mGluR II can be activated by ambient glutamate, we examined
A

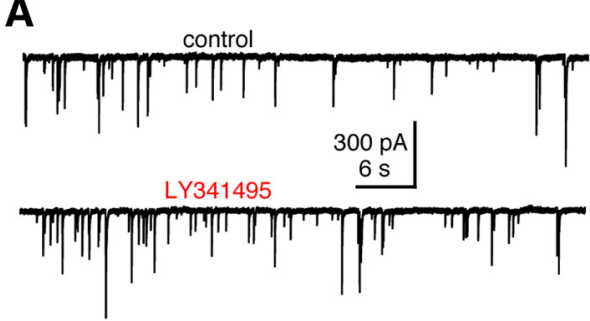

averaged SIPSC

\section{B}

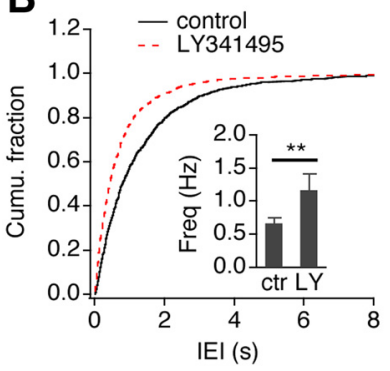

C

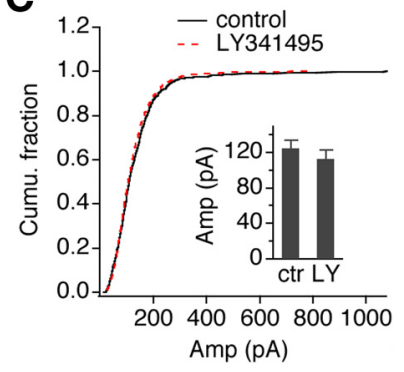

Figure 6. Ambient glutamate is sufficient in activating mGluR II. $A$, Representative sIPSCS recorded under control (ctr) and LY341495 (LY; $150 \mathrm{nm)}$ ) application. Shown on the right are the averaged traces under control and drug conditions (106 and 145 events, respectively). B, C, Cumulative fractions of the frequency (Freq) and amplitude (Amp) of sIPSCs show that LY341495 increased the frequency without affecting the amplitude of $\operatorname{SPSCs}(n=9)$. The insets show the averaged frequency and amplitude of sIPSCS $(n=9)$. IEl: Inter-event interval. ${ }^{* *} p<$ 0.01 ( $t$ test)

the effects of LY341495 on sIPSCs in NM neurons. LY341495 $(150 \mathrm{nM})$ increased the frequency (control, $0.66 \pm 0.09 \mathrm{~Hz}$; LY341495, $1.17 \pm 0.24 \mathrm{~Hz} ; n=9, p<0.01$; Fig. 6) without affecting the amplitude (control, $-124.0 \pm 9.4 \mathrm{pA}$; LY341495, $-112.5 \pm 10.4 \mathrm{pA} ; n=9, p>0.05$ ), suggesting that background ambient glutamate tonically activates presynaptic mGluR II, leading to suppression of spontaneous GABA release.

We next asked whether activation of mGluR II by endogenous glutamate could induce LTD at GABAergic synapses. To address this, we concurrently activated both the glutamatergic and GABAergic pathways evoking a synaptic current typically with a fast and a slow component (Fig. 7A,B). The fast component was abolished by DNQX $(50 \mu \mathrm{M})$, whereas the slow component was abolished by SR95531 $(10 \mu \mathrm{M})$, a selective $\mathrm{GABA}_{\mathrm{A}} \mathrm{R}$ antagonist. We then examined whether low-frequency stimulation (LFS; 1 $\mathrm{Hz}$, for $15 \mathrm{~min}$ ) applied to the two pathways induced LTD. The LFS protocol is commonly used to induce homosynaptic mGluR II-LTD at glutamatergic synapses (Kobayashi et al., 1996; Yokoi et al., 1996; Manahan-Vaughan, 1997; Domenici et al., 1998; Huang et al., 1999; Cho et al., 2000; Li et al., 2002). In the presence of APV $(50 \mu \mathrm{M})$, LFS induced a robust LTD $(n=11$; Fig. $7 C)$. We next determined whether LFS-induced LTD was attributable to activation of mGluR II by synaptically released glutamate. Because LY341495 can affect spontaneous GABA release (Fig. 6), we thus incubated the slices in ACSF containing LY341495 (200 nM) for $10 \mathrm{~min}$ before recordings of IPSCs started to eliminate the effects of tonic mGluR II activated by ambient glutamate. In the presence of LY341495, LFS failed to induce LTD ( $n=13$; Fig. $7 D$ ), suggesting that the LTD was induced by mGluR II activated by synaptically released glutamate. It is conceivable that the major source of glutamate needed to induce the LTD is from the auditory nerve, because the electrical stimulation applied to these cells coactivated both the excitatory and inhibitory inputs. However, it is still unknown whether ambient glutamate or other activity-independent pools of the transmitter is sufficient to in- 

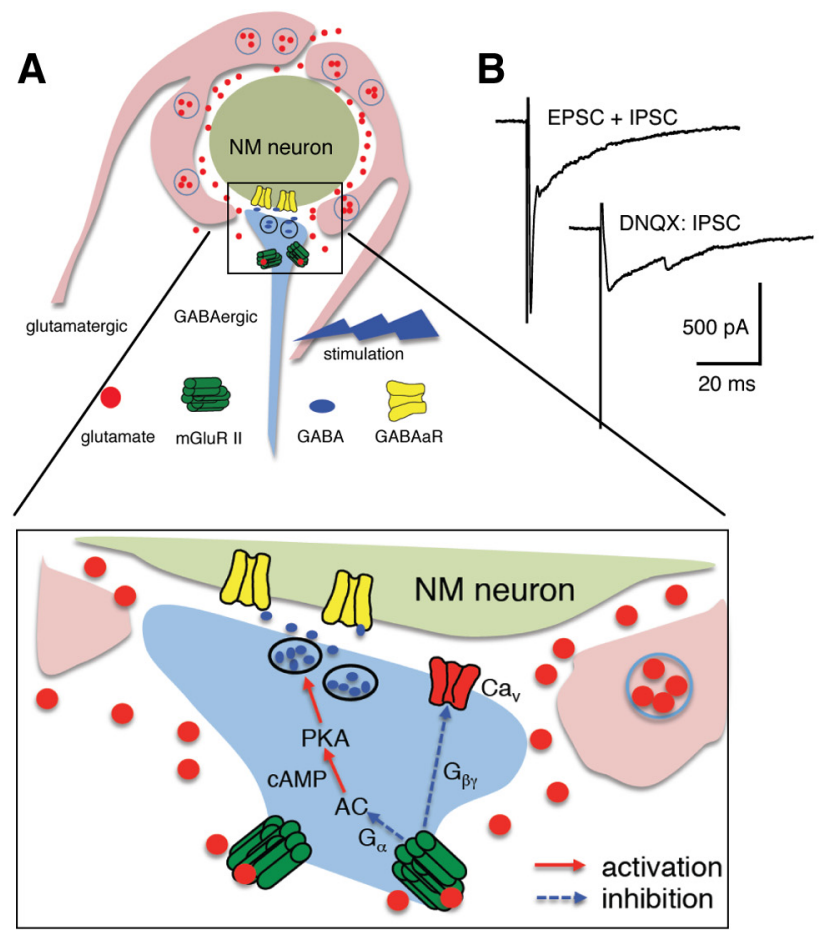

$\mathbf{F}$
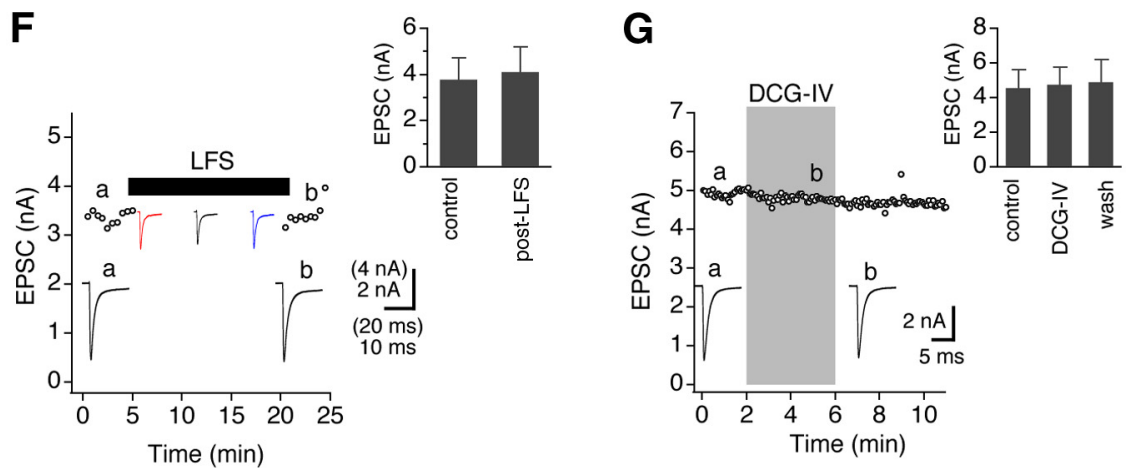

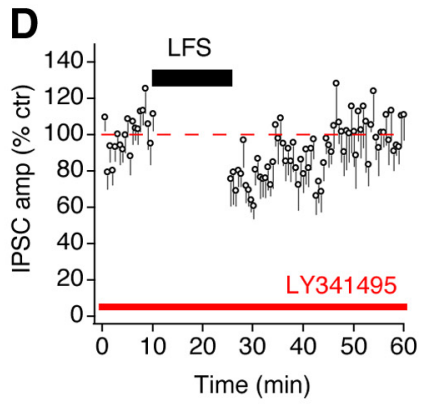

$\mathbf{E}$
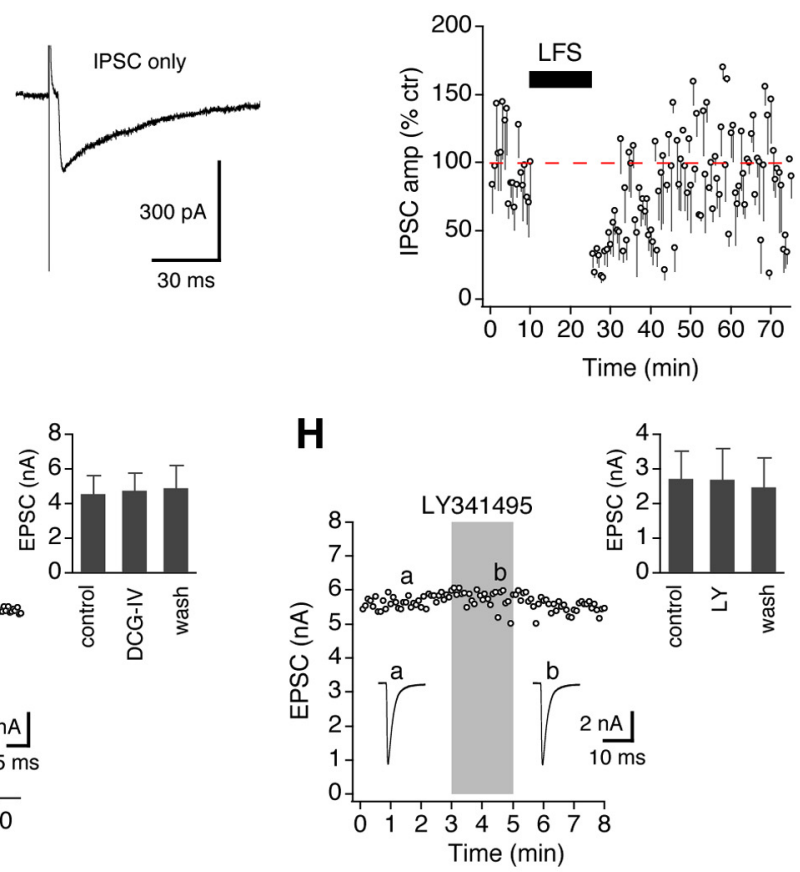

Figure 7. Synaptically released glutamate induces heterosynaptic mGluR II-LTD at GABAergic synapses. $A$, A schematic drawing showing the experimental paradigm and possible mechanisms underlying mGluR II-LTD of GABA release. B, Concurrent activation of the glutamatergic and GABAergic pathways. The EPSC was blocked by DNQX ( $50 \mu \mathrm{m})$. C, An LFS ( $1 \mathrm{~Hz}$, for $15 \mathrm{~min})$ induced LTD of IPSCS $(n=11)$. $\boldsymbol{D}$, The LTD was blocked by LY341495 (150 nM; $n=13)$, excluding electrical LTD and confirming chemical LTD induced by mGluR II. E, In cells in which only IPSCs were evoked intentionally, LFS elicited a short-term suppression but not an LTD of IPSCS $(n=7)$. $\boldsymbol{F}$, The same LFS protocol did not change EPSCs in NM neurons $(n=6)$. The three EPSC traces under the bar indicating LFS were individual traces obtained from different time points throughout the LFS application. $\mathbf{G}, \mathbf{H}$, Neither DCG-IV $(4 \mu \mathrm{M}, n=6)$ nor LY341495 (LY; $0.2 \mu \mathrm{M}, n=5)$ altered the amplitude of EPSCs in NM neurons.

duce LTD. To test this, we intentionally recorded from NM neurons in which only IPSCs were evoked and examined whether the LFS induced LTD in the absence of glutamate release from the auditory nerve innervating the recorded cells. As expected, the LFS elicited a short-term suppression but not an LTD of IPSCs (Fig. 7E), suggesting that spike activity-dependent glutamate release from the auditory nerve is necessary for the induction of the LTD.

To confirm that the LFS does not alter glutamatergic transmission, which could in turn impact synaptic inhibition, we tested the effect of the LFS on evoked EPSCs in NM neurons. The LFS $(1 \mathrm{~Hz}, 15 \mathrm{~min}$ ) did not affect the EPSCs of NM neurons (Fig. $7 F, n=6$ cells, paired $t$ test, $p>0.05$ ), indicating that the amount of glutamate release during the LFS protocol is relatively constant, and there is no significant synaptic depression of the excitatory transmission at the stimulus interval used (1 s). This is consistent with previous findings that this synapse has the capability of releasing glutamate at high probability, and synaptic depression does not emerge until the stimulus pulse interval is below $10 \mathrm{~ms}$ (i.e., stimulus frequency of $100 \mathrm{~Hz}$; Zhang and Trussell, 1994). Therefore, it is conceivable that a stabilized amount of mGluR II is constantly activated by synaptically released glutamate during the LFS protocol, inducing LTD of IPSCs.

An equally important issue is whether mGluR II activation affects the excitatory transmission during the LTD induction protocol, because mGluR II could alter glutamate release and in turn affect the GABAergic transmission. We found that DCG-IV $(4 \mu \mathrm{M})$ did not change the amplitude of EPSCs in NM neurons (Fig. $7 G, n=6$ cells, $p>0.05$ ). Otis and Trussell (1996) reported that ( \pm )-1-amino-1,3-cyclopentanedicarboxylic acid (200 $\mu \mathrm{M})$, a generic mGluR agonist that presumably activates all members of the three groups of mGluRs, did not change EPSCs in NM neurons. This is an unusual observation because mGluRs function as autoreceptors modulating glutamate release in many glutamate synapses in the CNS. Our results further confirmed the observation by Otis and Trussell (1996) and specifically demon- 
A1 control
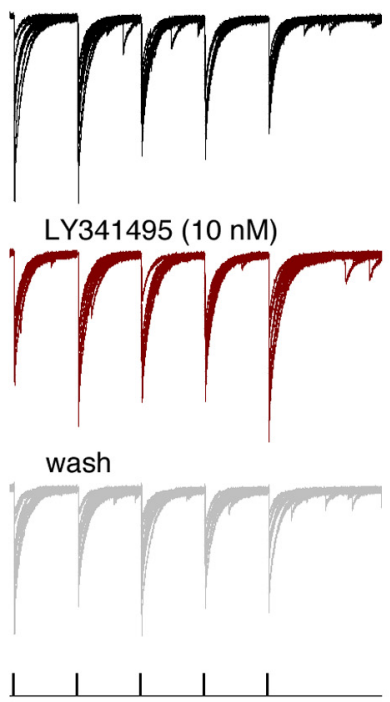

3.3 Hz (5 pulses)

B

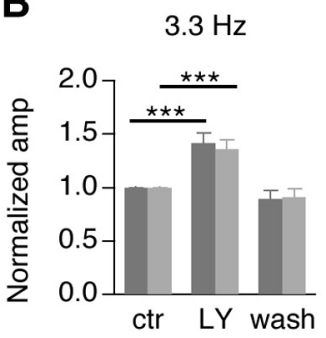

A2
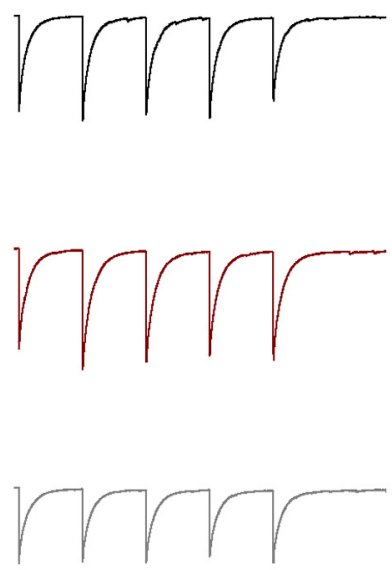

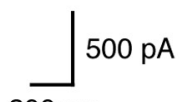

$200 \mathrm{~ms}$

C

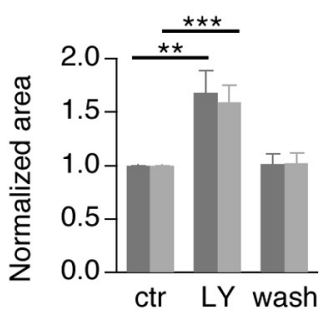

D - ctr

- LY

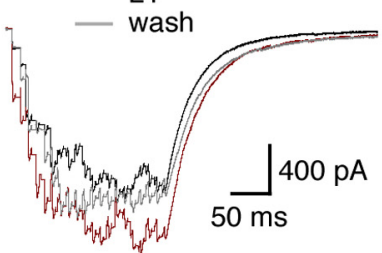

|||||||||||||||||||||

$100 \mathrm{~Hz}$ (20 pulses)

F

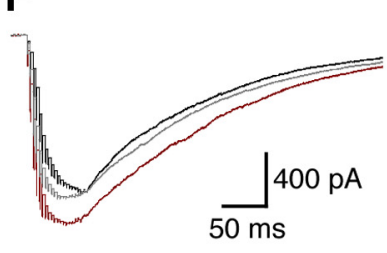

||||||||||||||||

$300 \mathrm{~Hz}$ (20 pulses)

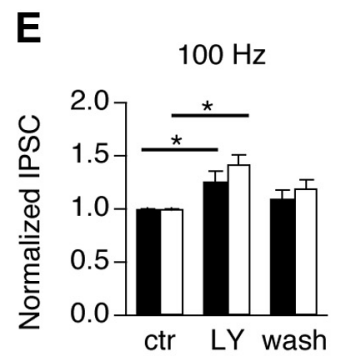

G

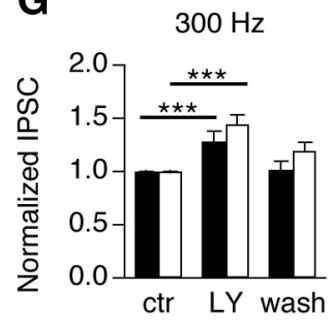

Figure 8. Synaptically released glutamate activates mGluR II independent of stimulus frequency. Train stimulations that caused concurrent activation of the glutamatergic and GABAergic pathways were used. $\boldsymbol{A}$, Superimposed original current traces evoked by a train stimulation at $3.3 \mathrm{~Hz}(\boldsymbol{A} \mathbf{1})$ and averaged IPSCs $(\boldsymbol{A} \mathbf{2})$ obtained under conditions of control, the mGluR II antagonist LY341495 (10 nM), and wash. A nearly complete recovery of the responses is observed after the washout. $B$, LY341495 (LY) significantly increases the normalized amplitude of IPSCs regardless of the presence of transmission failures ( $n=9$; dark gray: failures included, $p<0.001$; light gray: failures excluded, $p<0.001)$. Post hoc Fisher's analyses revealed significant differences in normalized IPSC amplitude between control (ctr) and LY341495. C, Consistently, LY341495 also significantly increases the normalized area (representing charge) of IPSCS ( $n=9$; dark gray: failures included, $p<0.01$; light gray: failures excluded, $p<0.001)$. D, E, LY341495 significantly increases the normalized amplitude (dark filled bars, $p=0.0116$ ) and area (open bars, $p<0.05$ ) of IPSCs elicited by train stimulation ( $100 \mathrm{~Hz}, 20$ pulses) ( $n=3) . F, G$, LY341495 significantly increases the normalized amplitude (dark solid bars, $p<0.0001$ ) and area (open bars, $p<0.0001)$ of IPSCs elicited by train stimulation $(300 \mathrm{~Hz}, 20$ pulses; $n=7)$. $\boldsymbol{H}$, No significant differences in the effects of LY341495 on the amplitude and area of IPSCs are detected under different stimulus frequencies. ${ }^{*} p<0.05$, ${ }^{* *} p<0.01,{ }^{* * *} p<0.001$ (ANOVA post hoc Fisher's test).

strated that mGluR II did not modulate glutamate release at NM. In addition, the mGluR II antagonist LY341495 $(0.2 \mu \mathrm{M})$ did not affect the EPSCs of NM neurons (Fig. $7 H, n=5$ cells, $p>0.05$ ). Together, these data (Fig. $7 C-H$ ) demonstrate that LFS of the glutamatergic pathway activates presynaptic mGluR II on GABAergic terminals and induces heterosynaptic LTD at GABAergic synapses, without modulating the excitatory inputs of NM neurons.

Finally, we tested whether synaptically released glutamate activates mGluR II, suppressing evoked GABA release in a stimulus frequency-dependent manner. The glutamatergic inputs to NM neurons are mediated by morphologically specialized presynaptic synapses, the end bulbs of Held, which cover the majority of the somata (Parks, 1981). With activation of the glutamatergic synapses, a high level of glutamate could be released and spilled to activate mGluRs on GABAergic terminals. We examined the effects of LY341495 on IPSCs evoked by train stimulations at different stimulus frequencies $(3.3,100$, or $300 \mathrm{~Hz})$. As expected, blocking mGluR II with LY341495 (10 nM) increased the amplitude of IPSCs (Fig. 8A-G). Because IPSCs evoked at 100 and 300 $\mathrm{Hz}$ summated temporally forming a plateau during the stimula- tion and a long decay time course, we also analyzed the IPSC area representing the total charge (product of time and current). Both the amplitude and the area of IPSCs showed a significant increase when mGluR II were blocked, demonstrating that synaptically released glutamate could activate mGluR II. Interestingly, the extent of activation of mGluR II and their modulatory strength on IPSCs were stimulus frequency independent (Fig. $8 H$ ), reflecting the high affinity of mGluR II in binding with glutamate and their readiness of being activated in NM neurons. In contrast, blocking mGluR III by CPPG (50 nM) significantly increased IPSCs at both stimulus frequencies of $3.3 \mathrm{~Hz}(n=7)$ and $100 \mathrm{~Hz}$ $(n=3)$, and the latter effect was significantly stronger than the former (data not shown).

In CA1 of the hippocampus, the form of long-term plasticity is dependent on stimulus frequency (Dudek and Bear, 1992). Because the LFS at $1 \mathrm{~Hz}$ elicited LTD and endogenous activity of mGluR II was detected at various stimulus frequencies $(3.3,100$, and $300 \mathrm{~Hz}$ ) in NM neurons, a logical question to ask next is whether the mGluR II-LTD is also stimulus frequency dependent. To address this, we tested whether a high-frequency stimulus $(100 \mathrm{~Hz}, 9 \mathrm{~s})$ that coactivated both the excitatory and 
A1
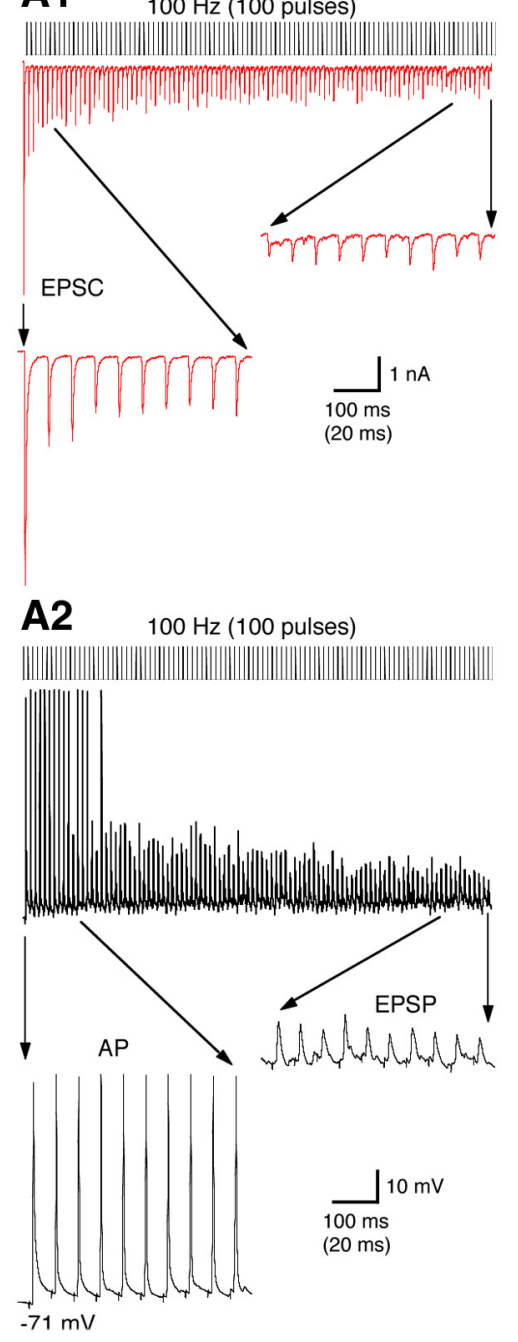
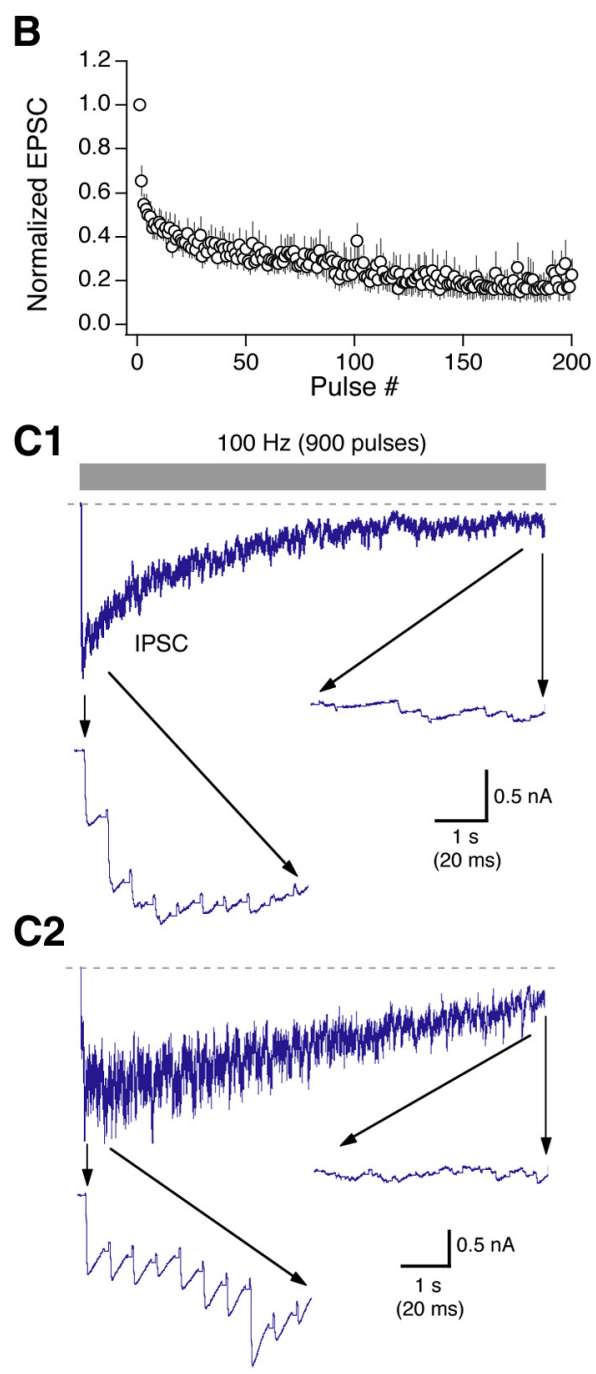

D

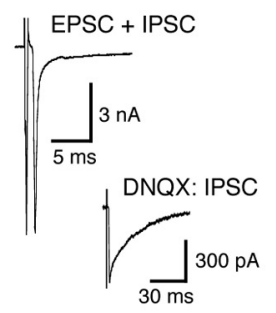

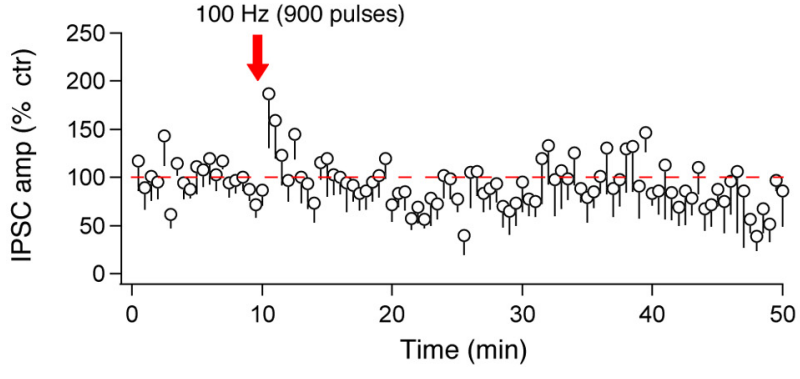

Figure 9. In slice preparations, a high-frequency electrical stimulation $(100 \mathrm{~Hz})$ rapidly diminishes synaptic currents. $\boldsymbol{A}$ 1, EPSCS of one NM neuron in response to a train stimulation ( $100 \mathrm{~Hz}, 100$ pulses). The first and the last 10 responses are shown at a larger timescale. By the end of the recording (duration of $1 \mathrm{~s}$ ), EPSCs diminish to a minimal level. $\boldsymbol{A 2}$, Correspondingly, in current-clamp recordings, a postsynaptic NM cell was driven by the same stimulus protocol to fire action potentials (APs) only at the beginning of the stimulation. A total of 10 and 5 cells were recorded in voltage- and current-clamp mode, respectively. $\boldsymbol{B}$, Normalized EPSC amplitudes plotted against stimulus pulse number $(n=10)$. C1, C2, IPSCs of two representative NM neurons in response to a train stimulation ( $100 \mathrm{~Hz}, 1000$ pulses). The first and the last 10 responses are shown at a larger timescale. Because of their slower kinetics, IPSCs temporally summated. The summated responses diminished to a level close to the baseline (indicated by the dashed line) in $\sim 10$ s. Individual IPSCs vary widely in their amplitudes, resulting in mixed short-term synaptic facilitation and depression. D, Concurrent activation of the glutamatergic and GABAergic pathways with train stimulation ( $100 \mathrm{~Hz}, 900$ pulses) does not induce any long-term plasticity of the IPSCS $(n=8)$. Stimulus artifacts in the EPSC and IPSC recordings are blanked for clarity.

inhibitory inputs to NM neurons induced LTD. The chosen stimulus frequency is physiologically relevant for both the excitatory inputs (Warchol and Dallos, 1990; Fukui et al., 2006) and the inhibitory inputs (Lachica et al., 1994; Coleman et al., 2011). The duration of the stimulation ( $9 \mathrm{~s}$ ) matched the number of pulses (900) in the LFS protocol (1 Hz, $15 \mathrm{~min})$, and the highfrequency stimulation protocol was used to characterize the glutamatergic and GABAergic responses. NM cells can readily sustain firing in vivo at rates at and above $100 \mathrm{~Hz}$. However, in slice preparations, electrical stimulation at $100 \mathrm{~Hz}$ rapidly diminished synaptic currents. Prominent synaptic depression of EPSCs occurred within the first 10 pulses, and by the end of $1 \mathrm{~s}$ of the recording, EPSCs diminished to the minimal level $(n=10$; Fig. 9A1,B). Correspondingly, NM neurons were driven to fire action potentials at the beginning of the train stimulation, followed by subthreshold EPSPs $(n=5$; Fig. 9A2). Similar results were obtained for IPSCs. Because of their slower kinetics, IPSCs temporally summated when stimulated at $100 \mathrm{~Hz}$ and decayed to a level close to the baseline in $9 \mathrm{~s}(n=8$; Fig. $9 C)$. Despite the apparent fast depletion of both transmitters in response to the train stimulation, concurrent activation of the glutamatergic and GABAergic pathways with the train stimulation $(100 \mathrm{~Hz}, 900$ pulses) caused a transient facilitation of IPSCs recorded with single-pulse stimulation. However, the train stimulation did not induce any long-term plasticity of the IPSCs $(n=8$; Fig. $9 D)$. The transient facilitation may be interpreted as a result of a large GABA release from replenished vesicle pools through a feedback mechanism after the train stimulation. The lack of long-term plasticity of the IPSCs suggests that the LTD may be stimulus frequency and duration dependent.

\section{Discussion}

We report a novel form of heterosynaptic long-term plasticity: mGluR II-LTD at GABAergic synapses in the central auditory system. This mGluR II-LTD can be induced by pharmacological or synaptic activation of mGluR II. Below we discuss the rigorous evidence we presented to establish the validity of the LTD, followed by assessment of the signaling pathway and functional implication.

\section{Establishment of mGluR II-LTD at GABAergic synapses}

Since its discovery (Palmer et al., 1997), chemical LTD has been studied extensively at glutamatergic synapses (Collingridge et al., 2010). However, there have been debates on whether chemical LTD is caused by incomplete washout of the agonists (Wostrack and Dietrich, 2009). The following results demonstrate that the LTD we observed is not an artifact of agonist treatment. First, 
application of the mGluR II antagonist LY341495 after washout of DCG-IV partially reversed the LTD (Fig. $1 \mathrm{~J}, K$ ), indicating the presence of an LTD insensitive to LY341495. The partial sensitivity of the LTD to LY341495 may be explained by constitutive activity of mGluR II in the absence of agonists (Lodge et al., 2013). Second, DCG-IV application without synaptic stimulation of the GABAergic afferents fails to induce LTD (Fig. 3A). Chelating $\mathrm{Ca}^{2+}$ in presumably all neuronal compartments using BAPTA-AM essentially eliminated the LTD, whereas chelating $\mathrm{Ca}^{2+}$ in postsynaptic cells using high EGTA did not (Fig. $3 D, E$ ), suggesting that both mGluR II activation and $\mathrm{Ca}^{2+}$ signaling in the GABAergic terminals are required. Third, blocking mGluR II (Figs. 1E, 7D) or candidate molecules suspected to be involved in the LTD pathway eliminates the LTD (Fig. $5 B, D$ ). The reversibility of the initial inhibition also indicates complete washout of DCG-IV. Fourth, physiologically released glutamate but not GABA induced LTD of GABA release (Fig. 7C,E), confirming chemical LTD induced by heteroreceptors and excluding electrical LTD induced by direct low-frequency activation of the GABA afferents (Gaiarsa et al., 2002). Finally, neither mGluR II agonist nor the LFS protocol affects glutamatergic transmission in NM (Fig. $7 F, G$ ), indicating that the LTD is formed at the GABAergic synapses rather than caused by altered glutamate release.

Endogenous glutamate readily activates mGluR II in NM neurons (Figs. 6-8), possibly because mGluR II have high affinity of binding glutamate (Cartmell and Schoepp, 2000). Glutamate required for the endogenous activation of mGluR II on the GABAergic terminals in NM could originate from several sources, such as ambient glutamate present in the extracellular space, synaptic release from the auditory nerve, and spillover from neighboring glutamatergic synapses or activity-independent release from glial cells. The observation that mGluR II antagonist enhanced the frequency without affecting the amplitude of sIPSC indicates that presynaptic mGluR II are activated tonically by ambient glutamate and exert a continued control of the basal level of GABA release. Blocking mGluR II increased the amplitude of IPSCs, regardless of stimulus frequencies $(3.3,100$, or $300 \mathrm{~Hz})$, indicating that mGluR II could be activated by synaptically released glutamate and probably reached saturation at low stimulus frequencies. Consequently, LFS applied to coactivate the glutamate and GABA pathways was able to trigger LTD, strongly indicating that synaptic activation of mGluR II caused a heterosynaptic LTD. Figure 10 schematically depicts the three components of the inhibition caused by mGluR II on the GABAergic transmission in NM. Ambient glutamate activates a proportion of the highaffinity mGluR II, suppressing the spontaneous GABA release. Similar tonic mGluR activity has been observed in dopamine neurons in the substantia nigra (Wang et al., 2005). When exogenous mGluR II agonists were added, a strong inhibition of IPSCs was produced. After washout of the agonists, the response recovered partially and remained constant afterward, suggesting the presence of LTD.

\section{Presynaptic expression and the cAMP/PKA signaling of the LTD}

The majority of mGluR II-LTD at glutamatergic synapses is expressed presynaptically (Bellone et al., 2008), whereas postsynaptic expression of mGluR II-LTD at some glutamatergic synapses was also reported (Huang et al., 1999; Cho et al., 2000; Otani et al., 2002). Several lines of evidence show that the induction of mGluR II-LTD of GABAergic synapses in NM is expressed presynaptically. First, mGluR II-LTD induced by either DCG-IV or LFS was accompanied by the increase in CV of IPSC amplitude

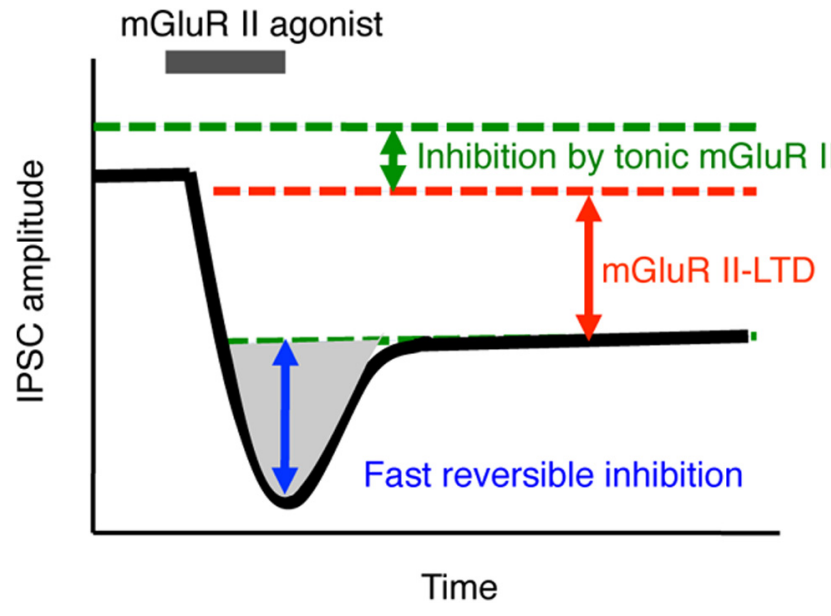

Figure 10. Schematic drawing depicting the three components of the inhibition caused by mGluR II on the GABAergic transmission in NM neurons. Ambient glutamate activates some mGluR II, suppressing the spontaneous release of GABA. Application of an exogenous mGluR II agonist produces a large inhibition of IPSCS, which consists of a reversible component and the LTD.

and failure rate of GABAergic responses. Second, the induction of mGluR II-LTD by DCG-IV was associated with minimal changes of postsynaptic neural excitability. Third, treatment of BAPTAAM, but not postsynaptically loaded EGTA, prevented mGluR II-LTD, suggesting that presynaptic $\mathrm{Ca}^{2+}$ signaling is involved. Finally, blocking mGluR II increased the frequency without affecting the amplitude of sIPSCs. Therefore, the mGluR II-LTD is primarily caused by a presynaptic persistent reduction in the probability of GABA release.

Multiple molecular mechanisms account for long-term changes at GABAergic synapses (Castillo et al., 2011). Being primarily coupled to $\mathrm{G}_{\mathrm{i}}$-proteins, mGluR II are negatively linked to $\mathrm{AC}$, leading to a reduction in the intracellular cAMP levels and inhibition of PKA (Pin and Acher, 2002), although PKC is involved in some cases (Otani et al., 1999; Kahn et al., 2001). Consequently, mGluR II-LTD at glutamatergic synapses is expressed through common signaling mechanisms involving cAMP/PKA (Tzounopoulos et al., 1998; Robbe et al., 2002; Chevaleyre and Castillo, 2003; Zhao and Tzounopoulos, 2011). The mGluR IILTD in NM neurons shares the same induction and expression mechanisms, because blocking AC or PKA abolished the LTD. Therefore, inhibition of cAMP/PKA activity may be a signal transduction mechanism by which mGluR II-LTD can be induced at both glutamatergic and GABAergic synapses. Other features of mGluR II-LTD at GABAergic synapses appear to be similar to mGluR II-LTD at glutamatergic synapses described previously in hippocampal CA3 (Tzounopoulos et al., 1998) and amygdala (Lin et al., 2000). Both forms of mGluR II-LTD require presynaptic spiking activity but do not require activation of NMDARs.

\section{Functional implications}

Long-term plasticity is commonly expressed in higher-order brain structures, such as the cerebral and cerebellar cortex, including the auditory cortex (Schreiner and Winer, 2007), in which synaptic plasticity is implicated in normal auditory signaling processing (Oda et al., 1998; Froemke et al., 2007) and hearing loss (Xu et al., 2010; Sanes and Kotak, 2011). In the past decade, such long-term plasticity has also been revealed in lower auditory brainstem (Tzounopoulos and Kraus, 2009), such as in the lateral 
superior olive (Kotak and Sanes 2000, 2002; Kotak et al., 2001; Chang et al. 2003) and in the dorsal cochlear nucleus (Fujino and Oertel, 2003; Tzounopoulos et al., 2004, 2007; Zhao and Tzounopoulos, 2011). However, in the auditory brainstem structures responsible for precise timing coding, such long-term plasticity was thought to be absent based on the assumption that highfidelity information transfer was so critical for temporal processing that long-term plasticity of neuronal properties could be counterproductive. Our results challenge this view by establishing that synaptic activation of mGluR II can form long-term modulatory action on GABAergic inputs in neurons that perform precise timing coding in the auditory brainstem.

Physiological functions of long-term plasticity at inhibitory synapses remain primarily elusive (Castillo et al., 2011). mGluRdependent LTD has been implicated in synaptic remodeling during development, especially at synapses in which such LTD is age dependent (Li et al., 2002). For instance, mGluR I/II-LTD of glutamate synapses is accompanied by synaptic elimination at CA3-CA1 synapses in hippocampus (Shinoda et al., 2005), and mGluR I-LTD contributes to synaptic elimination of climbing fiber synapses on cerebellar Purkinje neurons (Ichise et al., 2000). In the auditory system, LTD at inhibitory synapses may contribute to synaptogenesis and synaptic refinement (Kotak and Sanes, 2000; Kotak et al., 2001). NM neurons experience dramatic dendritic pruning during development, with extensive dendritic arborization in early embryos (E8-E13) and few short dendrites in late embryos (E16-E20; Jhaveri and Morest, 1982). mGluRmediated modulation of the GABAergic transmission is developmentally regulated during the period of dendritic pruning (Tang and Lu, 2012). Whether and how mGluR II-LTD of GABAergic synapses is involved in development, or in dendritic retraction after afferent deprivation (Wang and Rubel, 2012), remain to be investigated. In mature animals, we propose that such LTD prevents GABA spikes induced by overactivation of the GABAergic input (Lu and Trussell, 2001). Such a role supports our previously proposed model in which tonic activity of mGluRs regulates the basal level of GABA release, whereas a use-dependent activation of metabotropic GABA receptors provides a feedback control of GABA release in NM, ensuring high fidelity of phaselocking and precise temporal processing of sounds ( $\mathrm{Lu}, 2007$ ). Furthermore, NM neurons receive high rate inputs from the auditory nerve in vivo (Warchol and Dallos, 1990; Fukui et al., 2006), and a possible high level of tonic mGluR II activity would maintain the LTD at a constant state. Therefore, regulation of tonic mGluR II activity would be physiologically important for temporal coding, because variations in GABA release may generate patterned neuronal responses encoding dynamic temporal features of sound. Such regulation can be achieved at multiple stages along mGluR II signaling pathways by multiple G-proteincoupled receptors, which merits additional investigation to reveal the sophisticated yet synergetic actions of various neuromodulators in controlling synaptic strength in time-coding neurons.

\section{References}

Bellone C, Lüscher C, Mameli M (2008) Mechanisms of synaptic depression triggered by metabotropic glutamate receptors. Cell Mol Life Sci 65:29132923. CrossRef Medline

Breakwell NA, Huang L, Rowan MJ, Anwyl R (1997) DCG-IV inhibits synaptic transmission by activation of NMDA receptors in area CA1 of rat hippocampus. Eur J Pharmacol 322:173-178. CrossRef Medline

Brenowitz S, David J, Trussell L (1998) Enhancement of synaptic efficacy by presynaptic $\mathrm{GABA}_{\mathrm{B}}$ receptors. Neuron 20:135-141. CrossRef Medline

Burger RM, Cramer KS, Pfeiffer JD, Rubel EW (2005) Avian superior oli- vary nucleus provides divergent inhibitory input to parallel auditory pathways. J Comp Neurol 481:6-18. CrossRef Medline

Cartmell J, Schoepp DD (2000) Regulation of neurotransmitter release by metabotropic glutamate receptors. J Neurochem 75:889-907. CrossRef Medline

Castillo PE, Chiu CQ, Carroll RC (2011) Long-term plasticity at inhibitory synapses. Curr Opin Neurobiol 21:328-338. CrossRef Medline

Chang EH, Kotak VC, Sanes DH (2003) Long-term depression of synaptic inhibition is expressed postsynaptically in the developing auditory system. J Neurophysiol 90:1479-1488. CrossRef Medline

Chevaleyre V, Castillo PE (2003) Heterosynaptic LTD of hippocampal GABAergic synapses: a novel role of endocannabinoids in regulating excitability. Neuron 38:461-472. CrossRef Medline

Cho K, Kemp N, Noel J, Aggleton JP, Brown MW, Bashir ZI (2000) A new form of long-term depression in the perirhinal cortex. Nat Neurosci 3:150-156. CrossRef Medline

Chu Z, Moenter SM (2005) Endogenous activation of metabotropic glutamate receptors modulates GABAergic transmission to gonadotropinreleasing hormone neurons and alters their firing rate: a possible local feedback circuit. J Neurosci 25:5740-5749. CrossRef Medline

Code RA, Burd GD, Rubel EW (1989) Development of GABA immunoreactivity in brainstem auditory nuclei of the chick: ontogeny of gradients in terminal staining. J Comp Neurol 284:504-518. CrossRef Medline

Coleman WL, Fischl MJ, Weimann SR, Burger RM (2011) GABAergic and glycinergic inhibition modulate monaural auditory response properties in the avian superior olivary nucleus. J Neurophysiol 105:2405-2420. CrossRef Medline

Collingridge GL, Peineau S, Howland JG, Wang YT (2010) Long-term depression in the CNS. Nat Rev Neurosci 11:459-473. CrossRef Medline

Domenici MR, Berretta N, Cherubini E (1998) Two distinct forms of longterm depression coexist at the mossy fiber-CA3 synapse in the hippocampus during development. Proc Natl Acad Sci U S A 95:8310-8315. CrossRef Medline

Dudek SM, Bear MF (1992) Homosynaptic long-term depression in area CA1 of hippocampus and effects of $N$-methyl-D-aspartate receptor blockade. Proc Natl Acad Sci U S A 89:4363-4367. CrossRef Medline

Faber DS, Korn H (1991) Applicability of the coefficient of variation method for analyzing synaptic plasticity. Biophys J 60:1288-1294. CrossRef Medline

Froemke RC, Merzenich MM, Schreiner CE (2007) A synaptic memory trace for cortical receptive field plasticity. Nature 450:425-429. CrossRef Medline

Fujino K, Oertel D (2003) Bidirectional synaptic plasticity in the cerebellum-like mammalian dorsal cochlear nucleus. Proc Natl Acad Sci U S A 100:265-270. CrossRef Medline

Fukui I, Sato T, Ohmori H (2006) Improvement of phase information at low sound frequency in nucleus magnocellularis of the chicken. J Neurophysiol 96:633-641. CrossRef Medline

Gaiarsa JL, Caillard O, Ben-Ari Y (2002) Long-term plasticity at GABAergic and glycinergic synapses: mechanisms and functional significance. Trends Neurosci 25:564-570. CrossRef Medline

Herlitze S, Garcia DE, Mackie K, Hille B, Scheuer T, Catterall WA (1996) Modulation of $\mathrm{Ca}^{2+}$ channels by G-protein beta gamma subunits. Nature 380:258-262. CrossRef Medline

Huang CC, Yang PC, Lin HJ, Hsu KS (2007) Repeated cocaine administration impairs group II metabotropic glutamate receptor-mediated longterm depression in rat medial prefrontal cortex. J Neurosci 27:2958-2968. CrossRef Medline

Huang L, Killbride J, Rowan MJ, Anwyl R (1999) Activation of mGluRII induces LTD via activation of protein kinase $A$ and protein kinase $C$ in the dentate gyrus of the hippocampus in vitro. Neuropharmacology 38:7383. CrossRef Medline

Huang LQ, Rowan MJ, Anwyl R (1997) mGluR II agonist inhibition of LTP induction, and mGluR II antagonist inhibition of LTD induction, in the dentate gyrus in vitro. Neuroreport 8:687-693. CrossRef Medline

Ichise T, Kano M, Hashimoto K, Yanagihara D, Nakao K, Shigemoto R, Katsuki M, Aiba A (2000) mGluR1 in cerebellar Purkinje cells essential for long-term depression, synapse elimination, and motor coordination. Science 288:1832-1835. CrossRef Medline

Jhaveri S, Morest DK (1982) Sequential alterations of neuronal architecture in nucleus magnocellularis of the developing chicken: a Golgi study. Neuroscience 7:837-853. CrossRef Medline 
Jiang B, Huang S, de Pasquale R, Millman D, Song L, Lee HK, Tsumoto T, Kirkwood A (2010) The maturation of GABAergic transmission in visual cortex requires endocannabinoid-mediated LTD of inhibitory inputs during a critical period. Neuron 66:248-259. CrossRef Medline

Kahn L, Alonso G, Robbe D, Bockaert J, Manzoni OJ (2001) Group 2 metabotropic glutamate receptors induced long term depression in mouse striatal slices. Neurosci Lett 316:178-182. CrossRef Medline

Kobayashi K, Manabe T, Takahashi T (1996) Presynaptic long-term depression at the hippocampal mossy fiber-CA3 synapse. Science 273:648-650. CrossRef Medline

Kotak VC, Sanes DH (2000) Long-lasting inhibitory synaptic depression is age- and calcium-dependent. J Neurosci 20:5820-5826. Medline

Kotak VC, Sanes DH (2002) Postsynaptic kinase signaling underlies inhibitory synaptic plasticity in the lateral superior olive. J Neurobiol 53:3643. CrossRef Medline

Kotak VC, DiMattina C, Sanes DH (2001) $\mathrm{GABA}_{\mathrm{B}}$ and Trk receptor signaling mediates long-lasting inhibitory synaptic depression. J Neurophysiol 86:536-540. Medline

Kulla A, Reymann KG, Manahan-Vaughan D (1999) Time-dependent induction of depotentiation in the dentate gyrus of freely moving rats: involvement of group 2 metabotropic glutamate receptors. Eur J Neurosci 11:3864-3872. CrossRef Medline

Lachica EA, Rübsamen R, Rubel EW (1994) GABAergic terminals in nucleus magnocellularis and laminaris originate from the superior olivary nucleus. J Comp Neurol 348:403-418. CrossRef Medline

Li ST, Kato K, Tomizawa K, Matsushita M, Moriwaki A, Matsui H, Mikoshiba $\mathrm{K}$ (2002) Calcineurin plays different roles in group II metabotropic glutamate receptor- and NMDA receptor-dependent long-term depression. J Neurosci 22:5034-5041. Medline

Lien CC, Mu Y, Vargas-Caballero M, Poo MM (2006) Visual stimuliinduced LTD of GABAergic synapses mediated by presynaptic NMDA receptors. Nat Neurosci 9:372-380. CrossRef Medline

Lin HC, Wang SJ, Luo MZ, Gean PW (2000) Activation of group II metabotropic glutamate receptors induces long-term depression of synaptic transmission in the rat amygdala. J Neurosci 20:9017-9024. Medline

Lodge D, Tidball P, Mercier MS, Lucas SJ, Hanna L, Ceolin L, Kritikos M, Fitzjohn SM, Sherwood JL, Bannister N, Volianskis A, Jane DE, Bortolotto ZA, Collingridge GL (2013) Antagonists reversibly reverse chemical LTD induced by group I, group II and group III metabotropic glutamate receptors. Neuropharmacology 74:135-146. CrossRef Medline

Lu T, Trussell LO (2000) Inhibitory transmission mediated by asynchronous transmitter release. Neuron 26:683-694. CrossRef Medline

Lu T, Trussell LO (2001) Mixed excitatory and inhibitory GABA-mediated transmission in chick cochlear nucleus. J Physiol 535:125-131. CrossRef Medline

Lu Y (2007) Endogenous mGluR activity suppresses GABAergic transmission in avian cochlear nucleus magnocellularis neurons. J Neurophysiol 97:1018-1029. Medline

Lu Y, Rubel EW (2005) Activation of metabotropic glutamate receptors inhibits high-voltage-gated calcium channel currents of chicken nucleus magnocellularis neurons. J Neurophysiol 93:1418-1428. CrossRef Medline

Manahan-Vaughan D (1997) Group 1 and 2 metabotropic glutamate receptors play differential roles in hippocampal long-term depression and long-term potentiation in freely moving rats. J Neurosci 17:3303-3311. Medline

McCaffery B, Cho K, Bortolotto ZA, Aggleton JP, Brown MW, Conquet F, Collingridge GL, Bashir ZI (1999) Synaptic depression induced by pharmacological activation of metabotropic glutamate receptors in the perirhinal cortex in vitro. Neuroscience 93:977-984. CrossRef Medline

Mitchell SJ, Silver RA (2000) Glutamate spillover suppresses inhibition by activating presynaptic mGluRs. Nature 404:498-502. CrossRef Medline

Monsivais P, Rubel EW (2001) Accommodation enhances depolarizing inhibition in central neurons. J Neurosci 21:7823-7830. Medline

Neki A, Ohishi H, Kaneko T, Shigemoto R, Nakanishi S, Mizuno N (1996) Metabotropic glutamate receptors mGluR2 and mGluR5 are expressed in two non-overlapping populations of Golgi cells in the rat cerebellum. Neuroscience 75:815-826. CrossRef Medline

Nicoletti F, Bockaert J, Collingridge GL, Conn PJ, Ferraguti F, Schoepp DD, Wroblewski JT, Pin JP (2011) Metabotropic glutamate receptors: from the workbench to the bedside. Neuropharmacology 60:1017-1041. CrossRef Medline
Oda Y, Kawasaki K, Morita M, Korn H, Matsui H (1998) Inhibitory longterm potentiation underlies auditory conditioning of goldfish escape behaviour. Nature 394:182-185. CrossRef Medline

Ohishi H, Shigemoto R, Nakanishi S, Mizuno N (1993a) Distribution of the messenger RNA for a metabotropic glutamate receptor, mGluR2, in the central nervous system of the rat. Neuroscience 53:1009-1018. CrossRef Medline

Ohishi H, Shigemoto R, Nakanishi S, Mizuno N (1993b) Distribution of the mRNA for a metabotropic glutamate receptor (mGluR3) in the rat brain: an in situ hybridization study. J Comp Neurol 335:252-266. CrossRef Medline

Ohishi H, Neki A, Mizuno N (1998) Distribution of a metabotropic glutamate receptor, mGluR2, in the central nervous system of the rat and mouse: an immunohistochemical study with a monoclonal antibody. Neurosci Res 30:65-82. CrossRef Medline

Otani S, Auclair N, Desce JM, Roisin MP, Crépel F (1999) Dopamine receptors and groups I and II mGluRs cooperate for long-term depression induction in rat prefrontal cortex through converging postsynaptic activation of MAP kinase. J Neurosci 19:9788-9802. Medline

Otani S, Daniel H, Takita M, Crépel F (2002) Long-term depression induced by postsynaptic group II metabotropic glutamate receptors linked to phospholipase $\mathrm{C}$ and intracellular calcium rise in rat prefrontal cortex. J Neurosci 22:3434-3444. Medline

Otis TS, Trussell LO (1996) Inhibition of transmitter release shortens the duration of the excitatory synaptic current at a calyceal synapse. J Neurophysiol 76:3584-3588. Medline

Palmer MJ, Irving AJ, Seabrook GR, Jane DE, Collingridge GL (1997) The group I mGlu receptor agonist DHPG induces a novel form of LTD in the CA1 region of the hippocampus. Neuropharmacology 36:1517-1532. CrossRef Medline

Parks TN (1981) Changes in the length and organization of nucleus laminaris dendrites after unilateral otocyst ablation in chick embryos. J Comp Neurol 202:47-57. CrossRef Medline

Pin JP, Acher F (2002) The metabotropic glutamate receptors: structure, activation mechanism and pharmacology. Curr Drug Targets CNS Neurol Disord 1:297-317. CrossRef Medline

Pöschel B, Manahan-Vaughan D (2005) Group II mGluR-induced long term depression in the dentate gyrus in vivo is NMDA receptorindependent and does not require protein synthesis. Neuropharmacology 49 [Suppl 1]:1-12. CrossRef

Robbe D, Bockaert J, Manzoni OJ (2002) Metabotropic glutamate receptor 2/3-dependent long-term depression in the nucleus accumbens is blocked in morphine withdrawn mice. Eur J Neurosci 16:2231-2235. CrossRef Medline

Rubel EW, Fritzsch B (2002) Auditory system development: primary auditory neurons and their targets. Annu Rev Neurosci 25:51-101. CrossRef Medline

Ryugo DK, Parks TN (2003) Primary innervation of the avian and mammalian cochlear nucleus. Brain Res Bull 60:435-456. CrossRef Medline

Sanes DH, Kotak VC (2011) Developmental plasticity of auditory cortical inhibitory synapses. Hear Res 279:140-148. CrossRef Medline

Schoepp DD, Johnson BG, Wright RA, Salhoff CR, Mayne NG, Wu S, Cockerman SL, Burnett JP, Belegaje R, Bleakman D, Monn JA (1997) LY354740 is a potent and highly selective group II metabotropic glutamate receptor agonist in cells expressing human glutamate receptors. Neuropharmacology 36:1-11. CrossRef Medline

Schoepp DD, Jane DE, Monn JA (1999) Pharmacological agents acting at subtypes of metabotropic glutamate receptors. Neuropharmacology 38 : 1431-1476. CrossRef Medline

Schreiner CE, Winer JA (2007) Auditory cortex mapmaking: principles, projections, and plasticity. Neuron 56:356-365. CrossRef Medline

Shigemoto R, Kinoshita A, Wada E, Nomura S, Ohishi H, Takada M, Flor PJ, Neki A, Abe T, Nakanishi S, Mizuno N (1997) Differential presynaptic localization of metabotropic glutamate receptor subtypes in the rat hippocampus. J Neurosci 17:7503-7522. Medline

Shinoda Y, Kamikubo Y, Egashira Y, Tominaga-Yoshino K, Ogura A (2005) Repetition of mGluR-dependent LTD causes slowly developing persistent reduction in synaptic strength accompanied by synapse elimination. Brain Res 1042:99-107. CrossRef Medline

Tang ZQ, Lu Y (2012) Development of GPCR modulation of GABAergic transmission in chicken nucleus laminaris neurons. PloS One 7:e35831. CrossRef Medline 
Tang ZQ, Gao H, Lu Y (2009) Control of a depolarizing GABAergic input in an auditory coincidence detection circuit. J Neurophysiol 102:1672-1683. CrossRef Medline

Tang ZQ, Dinh EH, Shi W, Lu Y (2011) Ambient GABA-activated tonic inhibition sharpens auditory coincidence detection via a depolarizing shunting mechanism. J Neurosci 31:6121-6131. CrossRef Medline

Tzounopoulos T, Kraus N (2009) Learning to encode timing: mechanisms of plasticity in the auditory brainstem. Neuron 62:463-469. CrossRef Medline

Tzounopoulos T, Janz R, Südhof TC, Nicoll RA, Malenka RC (1998) A role for cAMP in long-term depression at hippocampal mossy fiber synapses. Neuron 21:837-845. CrossRef Medline

Tzounopoulos T, Kim Y, Oertel D, Trussell LO (2004) Cell-specific, spike timing-dependent plasticities in the dorsal cochlear nucleus. Nat Neurosci 7:719-725. CrossRef Medline

Tzounopoulos T, Rubio ME, Keen JE, Trussell LO (2007) Coactivation of pre- and postsynaptic signaling mechanisms determines cell-specific spike-timing-dependent plasticity. Neuron 54:291-301. CrossRef Medline

Wang L, Kitai ST, Xiang Z (2005) Modulation of excitatory synaptic transmission by endogenous glutamate acting on presynaptic group II mGluRs in rat substantia nigra compacta. J Neurosci Res 82:778-787. CrossRef Medline

Wang S, Chen X, Kurada L, Huang Z, Lei S (2012) Activation of group II metabotropic glutamate receptors inhibits glutamatergic transmission in the rat entorhinal cortex via reduction of glutamate release probability. Cereb Cortex 22:584-594. CrossRef Medline

Wang Y, Rubel EW (2012) In vivo reversible regulation of dendritic pattern- ing by afferent input in bipolar auditory neurons. J Neurosci 32:1149511504. CrossRef Medline

Warchol ME, Dallos P (1990) Neural coding in the chick cochlear nucleus. J Comp Physiol A Neuroethol Sens Neural Behav Physiol 166:721-734. Medline

Wilsch VW, Pidoplichko VI, Opitz T, Shinozaki H, Reymann KG (1994) Metabotropic glutamate receptor agonist DCG-IV as NMDA receptor agonist in immature rat hippocampal neurons. Eur J Pharmacol 262:287291. CrossRef Medline

Wostrack M, Dietrich D (2009) Involvement of Group II mGluRs in mossy fiber LTD. Synapse 63:1060-1068. CrossRef Medline

$\mathrm{Xu} \mathrm{H}$, Kotak VC, Sanes DH (2010) Normal hearing is required for the emergence of long-lasting inhibitory potentiation in cortex. J Neurosci 30:331341. CrossRef Medline

Yang L, Monsivais P, Rubel EW (1999) The superior olivary nucleus and its influence on nucleus laminaris: a source of inhibitory feedback for coincidence detection in the avian auditory brainstem. J Neurosci 19:23132325. Medline

Yokoi M, Kobayashi K, Manabe T, Takahashi T, Sakaguchi I, Katsuura G, Shigemoto R, Ohishi H, Nomura S, Nakamura K, Nakao K, Katsuki M, Nakanishi S (1996) Impairment of hippocampal mossy fiber LTD in mice lacking mGluR2. Science 273:645-647. CrossRef Medline

Zhang S, Trussell LO (1994) Voltage clamp analysis of excitatory synaptic transmission in the avian nucleus magnocellularis. J Physiol 480:123-136. Medline

Zhao Y, Tzounopoulos T (2011) Physiological activation of cholinergic inputs controls associative synaptic plasticity via modulation of endocannabinoid signaling. J Neurosci 31:3158-3168. CrossRef Medline 